Article

\title{
Scattering Characteristics of X-, C- and L-Band PolSAR Data Examined for the Tundra Environment of the Tuktoyaktuk Peninsula, Canada
}

\author{
Tobias Ullmann ${ }^{1, *}$, Sarah N. Banks ${ }^{2}$, Andreas Schmitt ${ }^{3}$ and Thomas Jagdhuber ${ }^{4}$ \\ 1 Institute Geography and Geology, University of Wuerzburg, D-97074 Wuerzburg, Germany \\ 2 National Wildlife Research Center (NWRC), Carleton University, Ottawa, ON K1A 0H3, Canada; \\ sbanks@connect.carleton.da \\ 3 Department of Geoinformatics, University of Applied Sciences Munich, D-80333 Munich, Germany; \\ andreas.schmitt@hm.edu \\ 4 German Aerospace Center (DLR), Microwaves and Radar Institute, D-82234 Wessling, Germany; \\ thomas.jagdhuber@dlr.de \\ * Correspondence: tobias.ullmann@uni-wuerzburg.de; Tel.: +49-931-31-86865
}

Academic Editor: Carlos López-Martínez

Received: 27 April 2017; Accepted: 3 June 2017; Published: 8 June 2017

\begin{abstract}
In this study, polarimetric Synthetic Aperture Radar (PolSAR) data at X-, C- and L-Bands, acquired by the satellites: TerraSAR-X (2011), Radarsat-2 (2011), ALOS (2010) and ALOS-2 (2016), were used to characterize the tundra land cover of a test site located close to the town of Tuktoyaktuk, NWT, Canada. Using available in situ ground data collected in 2010 and 2012, we investigate PolSAR scattering characteristics of common tundra land cover classes at X-, C- and L-Bands. Several decomposition features of quad-, co-, and cross-polarized data were compared, the correlation between them was investigated, and the class separability offered by their different feature spaces was analyzed. Certain PolSAR features at each wavelength were sensitive to the land cover and exhibited distinct scattering characteristics. Use of shorter wavelength imagery ( $X$ and $C$ ) was beneficial for the characterization of wetland and tundra vegetation, while L-Band data highlighted differences of the bare ground classes better. The Kennaugh Matrix decomposition applied in this study provided a unified framework to store, process, and analyze all data consistently, and the matrix offered a favorable feature space for class separation. Of all elements of the quad-polarized Kennaugh Matrix, the intensity based elements K0, K1, K2, K3 and K4 were found to be most valuable for class discrimination. These elements contributed to better class separation as indicated by an increase of the separability metrics squared Jefferys Matusita Distance and Transformed Divergence. The increase in separability was up to $57 \%$ for Radarsat- 2 and up to $18 \%$ for ALOS-2 data.
\end{abstract}

Keywords: PolSAR; dual polarimetry; quad polarimetry; decomposition; TerraSAR-X; Radarsat-2; ALOS; ALOS-2; tundra; arctic

\section{Introduction}

Polarimetric Synthetic Aperture Radar (PolSAR) data from an increasing number of different satellite systems has become available — or will become available in the near future-for up-to-date Earth observation and environmental monitoring. Microwave data, e.g., acquired by Sentinel-1, ALOS-2, or in the future, by the RADARSAT Constellation Mission, are capable of delivering remote sensing data at high spatial $(<10 \mathrm{~m})$ and temporal resolutions ( $<10$ days); independent of weather and illumination conditions. Therefore they are well suited for characterizing and monitoring the dynamic nature of the land surface, especially in vast and remote regions like the Arctic. In light of the challenges associated with a changing climate and environment, such investigations are crucial for assessing and 
comprehending temporal and spatial changes. Several studies have therefore investigated the use of SAR, PolSAR, and SAR interferometry (InSAR) for characterizing Arctic land surfaces, particularly that of tundra environments.

Table 1 provides an overview of select studies that involved the use of active microwave imaging of Arctic tundra environments. As can be observed, shortwave C- and X-Band data were frequently used for the characterization of land cover and shoreline types, and most studies incorporated analysis of polarimetric information to relate observed values with certain types or states of the land surface [1-16]. C-Band and L-Band data stacks have been used primarily to determine surface movements in permafrost regions using interferometry [17-21]. This is likely driven by the opening of the ALOS archive and the capacity of the L-Band microwaves to penetrate the relatively small tundra vegetation, typically resulting in higher interferometric coherence, and leading to a more reliable estimate of surface movements. The seasonal thawing and freezing of the active layer is also a promising area for InSAR applications, and estimation of the active layer thickness/variations across the entirety of the Arctic is of particular importance considering recent warming trends [22-24].

Table 1. Select studies that employed Synthetic Aperture Radar (SAR), polarimetric SAR (PolSAR) and InSAR (SAR interferometry) data and methods for the characterization of tundra (permafrost) landscapes and their dynamics; ERS: European Remote Sensing Satellite; R-1: Radarsat-1; TSX: TerraSAR-X; R-2: Radarsat-2; ALOS: Advanced Land Observing Satellite.

\begin{tabular}{|c|c|c|c|}
\hline Study Area & Sensor & Task and Method & Year and Reference \\
\hline Alaska, USA & ERS & $\begin{array}{l}\text { Bathymetric mapping of shallow water } \\
\text { via time series Analysis }\end{array}$ & $1996 \& 2000[1,2]$ \\
\hline $\begin{array}{l}\text { Mackenzie Delta } \\
\text { Region, Canada }\end{array}$ & ERS & Delineation of delta ecozones via InSAR-Coherence & $2001[3]$ \\
\hline Nova Scotia, Canada & R-1 & $\begin{array}{l}\text { Mapping of geomorphological units } \\
\text { in the intertidal zone via unsupervised classification }\end{array}$ & $2001[4]$ \\
\hline Quebec, Canada & TSX & Monitoring of permafrost dynamics via InSAR & $2011[5]$ \\
\hline $\begin{array}{l}\text { Herschel Island, } \\
\text { Canada }\end{array}$ & $\begin{array}{c}\text { TSX } \\
\text { R-2 } \\
\text { ALOS }\end{array}$ & Monitoring of surface movements via InSAR & $2009 \& 2011[16,17]$ \\
\hline $\begin{array}{l}\text { Mackenzie Delta } \\
\text { Region, Canada }\end{array}$ & $\mathrm{R}-2$ & $\begin{array}{l}\text { Classification of tundra land cover } \\
\text { and shoreline types via PolSAR }\end{array}$ & $2011 \& 2014[6,7]$ \\
\hline Lena Delta, Russia & $\begin{array}{l}\text { TSX } \\
\text { R-2 }\end{array}$ & $\begin{array}{l}\text { Characterization of melt onset and } \\
\text { geomorphological units via PolSAR }\end{array}$ & $2012[8]$ \\
\hline Alaska, USA & TSX & $\begin{array}{l}\text { Characterization of post-drainage succession } \\
\text { via time series analysis and PolSAR }\end{array}$ & $2012[9]$ \\
\hline Sodankylä, Finland & $\mathrm{R}-2$ & Identification of soil freezing and thawing states & 2014 [10] \\
\hline $\begin{array}{l}\text { Richards Island, } \\
\text { Canada }\end{array}$ & $\begin{array}{l}\text { TSX } \\
\text { R-2 }\end{array}$ & Classification of tundra land cover via PolSAR & 2014 [11] \\
\hline Baffin Island, Canada & $\mathrm{R}-2$ & Monitoring of surface movements via InSAR & $2014[18]$ \\
\hline Northern Canada & $\mathrm{R}-2$ & Modeling of phytomass via PolSAR & 2014 [12] \\
\hline $\begin{array}{l}\text { Dease Strait, Nunavut, } \\
\text { Canada }\end{array}$ & $\mathrm{R}-2$ & Classification of shoreline types via PolSAR & 2015 [13] \\
\hline Barrow, Alaska & ALOS & Active-layer thickness estimation via InSAR & 2015 [19] \\
\hline $\begin{array}{l}\text { Mackenzie Delta } \\
\text { Region, Canada }\end{array}$ & $\begin{array}{l}\text { TSX } \\
\text { R-2 }\end{array}$ & Characterization of tundra land cover via PolSAR & $2016[14]$ \\
\hline Northern Alaska, USA & ALOS & $\begin{array}{l}\text { Active-layer change and } \\
\text { subsidence monitoring via InSAR }\end{array}$ & 2016 [20] \\
\hline $\begin{array}{c}\text { Northern } \\
\text { Qinghai-Tibetan } \\
\text { Plateau }\end{array}$ & ALOS & Active-layer change via InSAR & $2017[21]$ \\
\hline $\begin{array}{l}\text { Yamal Peninsula, } \\
\text { Russia }\end{array}$ & TSX & $\begin{array}{l}\text { Active-layer thickness estimation } \\
\text { via backscatter intensity }\end{array}$ & 2017 [15] \\
\hline
\end{tabular}

Most of the studies identified in Table 1, employed data of a single sensor and only few involved multi-frequency SAR/PolSAR/InSAR information, e.g., dealing with some combination of X-, C- or L-Band data $[8,11,14,17]$. Among the selected studies, the quad-polarization mode of Radarsat-2 was most frequently employed, followed by the dual HH/HV-polarization mode of ALOS and TerraSAR-X, 
and the dual HH/VV-polarization mode of TerraSAR-X. For these different datasets, several polarimetric decomposition approaches were applied, including: the Eigen-decomposition (with the features Entropy, Anisotropy and Alpha Scattering Angle) [25,26], the Yamaguchi Decomposition [27], the Freeman-Durden Decomposition [28], and the Touzi Decomposition [29]. Two decomposition models for HH/VV-polarized data were further proposed by [30] and recently by [14].

In light of this previous research, and our preliminary investigations $[6,7,11,13,14]$, we analyze X-, C- and L-Band PolSAR data in order to characterize scattering properties of select tundra land cover classes for a test site in the Arctic. In addition, this study incorporates quad-polarized data of ALOS-2, a novel compilation of in situ data for the test site, and a complete utilization of the Kennaugh Matrix approach, recently presented by [31]. The Kennaugh Matrix approach offers a unified framework for processing polarimetric information of different polarization modes (quad-, dual- and compact-polarized data). It can be used to represent targets both incoherently and coherently, and can be converted into all of the well-established decomposition models, for all wavelengths [25]. Information on the Kennaugh Matrix framework is provided in the subsequent Section 2.2.2 Polarimetric SAR Data and Decompositions of this manuscript and in Appendix A.

The objectives of this research are therefore: First, process and analyze decomposition features of quad- and dual-polarized data of different sensors at three different frequencies. Second, investigate the backscattering of generalized tundra land cover classes for quad- and dual-polarized data of X-, C- and L-Band data. Third, investigate the correlation among PolSAR features of quad- and dual-polarized decomposition techniques. Fourth, benchmark and rank all PolSAR (decomposition) features in terms of class separability, and identify feature spaces and parameters that are most meaningful for characterizing the tundra land cover.

This manuscript is structured as follows: The subsequent section provides details on the materials and methods, as well as information on the location and environment of the test site selected for this research. Further, this section describes and lists the available land cover reference information, and the PolSAR data, including: quad- and dual-polarized data of Radarsat-2 (R-2), TerraSAR-X (TSX), ALOS and ALOS-2. Subsequently, the data processing and all polarimetric decompositions applied to the data are described, as well as separability measures/metrics used to analyse them, including: Transformed Divergence and Jefferys Matusita Distance.

The third section presents the results of the correlation analyses of C-Band R-2 and L-Band ALOS-2 data. Backscatter characteristics and select decomposition features of the land cover classes are presented and analysed via box- and scatterplots for X-, C- and L-Band data. Afterward, the results of the separability analysis and the feature selection are presented. Section four discusses the main findings, while section five provides a summary of the study; major conclusions are drawn and an outlook on future work is given.

\section{Materials and Methods}

\subsection{Test Site Description}

The study area is located at the northern extent of the mainland of the Northwest Territories, Canada (see Figure 1a). The region is part of the Canadian Arctic and lies entirely north of the tree-line along the coastal tundra plains of the Southern Arctic Ecozone [32]. The climate here is characterized cold winters, followed by short and cool summers. The mean annual air temperature at the climate station Tuktoyaktuk is $-1{ }^{\circ} \mathrm{C}$ (1971-2000), and the mean air temperature between October and April is below $-10{ }^{\circ} \mathrm{C}$. The average precipitation is about $150 \mathrm{~mm}$ [33]. The ground surface is characterized by the presence of continuous permafrost and its thickness is estimated to be up to $600 \mathrm{~m}$ [34]. Therefore, the soils of the Tuktoyaktuk Peninsula are Cryosols, with an active layer thickness of several centimeters to decimeters. The soils developed on glacial deposits of Pleistocene to Holocene age [32], and current morphodynamics are dominated by periglacial processes. The land surface is therefore characterized by low-lying and flat coastal plains, rolling hills, thermokarst lakes 
and pingos, and extensive networks of high- and low-centered ice wedges [33]. The ground surface is also characterized by tundra vegetation, with upland tundra usually composed of short herbaceous vegetation and shrubs (dwarf shrubs up to tall shrubs). The wetland vegetation (grasses, sedges or rushes) is frequently at or near water bodies, e.g., at drained lakes, or in the flat and low-lying intertidal zone. Depending on the coastal currents, the beach zone is characterized by fine sandy material, mixed sediments dominated by gravel, pebble or cobble and driftwood accumulations [33].
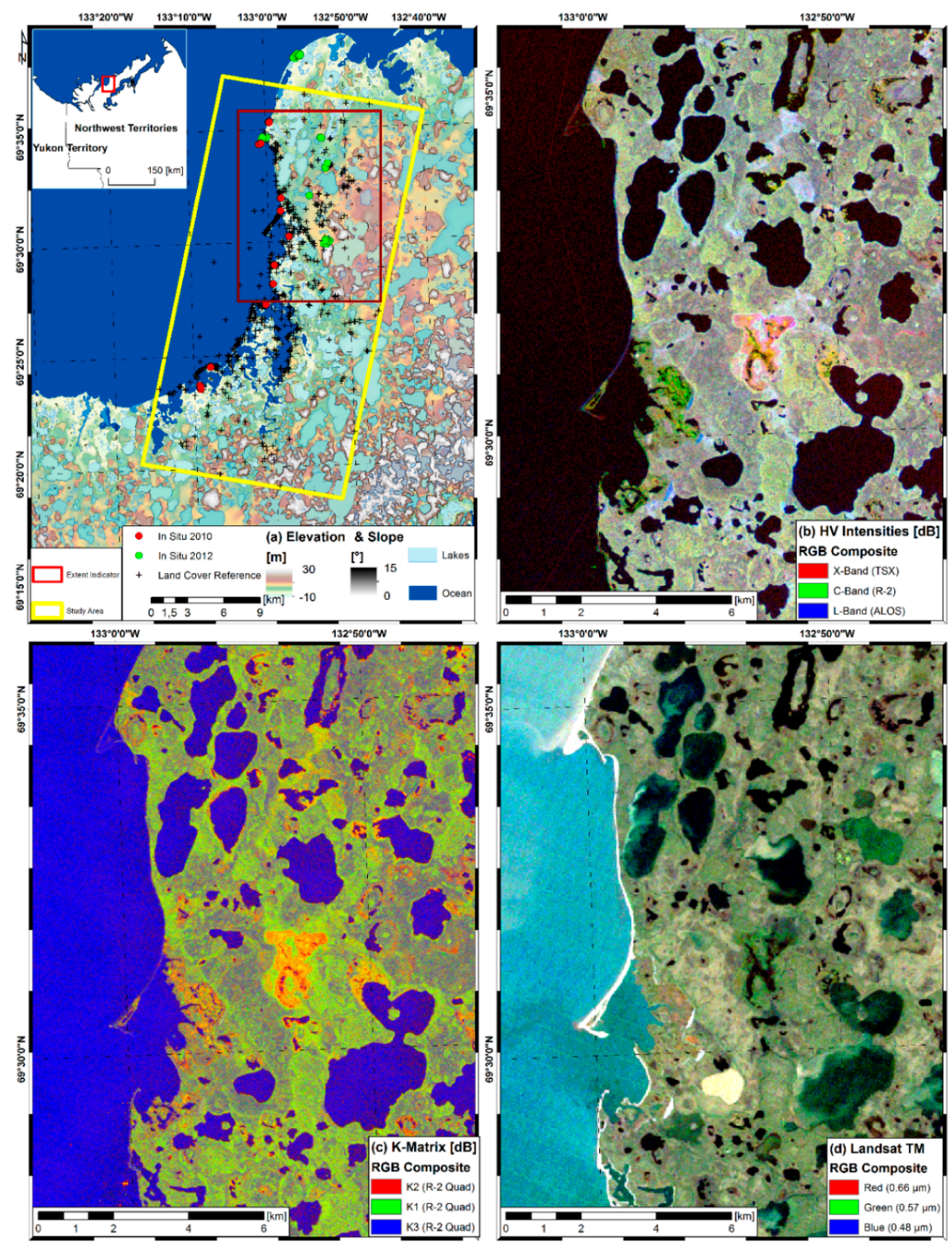

Figure 1. Location of the test site: Tuktoyaktuk (Northwest Territories, Canada) and RGB composites of remote sensing imagery: (a) elevation and slope of intermediate TanDEM-X DEM, coverage of TerraSAR-X, Radasat-2, ALOS and ALOS-2 imagery, locations of in situ field work in 2010 and 2012 , locations of land cover reference samples derived from high resolution ortho-photos, extent indicator of the subsequent sub-figures (red rectangle); (b) RGB false-color composite of sigma nought HV intensities [dB] of X-Band (TerraSAR-X, 2011), C-Band (Radarsat-2, 2011) and L-Band (ALOS, 2010); (c) RGB false-color composite of Kennaugh Matrix Elements K2, K1 and K3 of quad-polarized Radarsat-2 data (see Section 2.2.2 Polarimetric SAR Data and Decompositions for more details on the Kennaugh Matrix Elements); (d) Landsat TM (2011) true-color composite of red, green and blue surface reflectance. RGB channels are stretched linearly between 1 and $99 \%$ of the data range. 


\subsection{Database}

\subsubsection{Land Cover Reference}

In situ data on the land cover of the test site was acquired during two ground truth campaigns in the summer months of 2010 and 2012. The field work was organized and conducted by Carleton University, (Ottawa, ON, Canada), the NWRC (National Wildlife Research Centre, Ottawa, ON, Canada), and the University of Wuerzburg (Institute of Geography and Geology, Wuerzburg, Germany). Combining the land cover information of our preliminary studies $[6,7,11,14]$, the land cover reference was merged to a common database showing the eight land cover classes listed and described in Table 2. During the field campaigns information on the land cover of representative homogenous locations was recorded, categorized and mapped. The in situ classification of the land cover was completed by field experts, and within the frameworks of $[35,36]$. As specified in Table 2 the cut off criteria for the separation of Shrub (ST) and Herb Dominated Tundra (HT) was the presence of dwarf shrubs with a height greater or less than $0.25 \mathrm{~m}$. The separation between Sand (BS) and Mixed Sediment (BM) was based on the presence of pebble, which had to cover $>50 \%$ of the surface; the bare ground samples were considered homogeneous if $10 \%$ or less were "other" materials or vegetation. Locations were classified as Driftwood Accumulation (BW) if more than $80 \%$ of the ground were cover by driftwood. Wetland Vegetation Communities (WT) were dominated by grasses, sedges or rushes and frequently occurred inland at creeks and drained lakes. The locations classified as Inundated Low Lying Tundra (WI) exhibited tundra vegetation communities at or near a water body and were most prominent in the low-lying coastal supratidal north of the town of Tuktoyaktuk.

Table 2. Land cover classes considered in the analysis; description, class abbreviations (Abbr.), and class color coding. Bare Ground samples were considered homogeneous if $10 \%$ or less were "other" materials or vegetation. The letters " $\mathrm{W}$ ", " $\mathrm{B}$ ", " $\mathrm{T}$ " of the class abbreviations refer to Wetland, Bare Ground, and Tundra land cover classes.

\begin{tabular}{|c|c|c|c|c|}
\hline \multicolumn{2}{|c|}{ Land Cover Class Name } & \multirow{2}{*}{$\begin{array}{c}\text { Description } \\
\text { upland tundra composed of } \\
\text { short herbaceous vegetation } \\
\text { and low shrubs }(<25 \mathrm{~cm})\end{array}$} & \multirow{2}{*}{$\begin{array}{l}\text { Abbr. } \\
\text { HT }\end{array}$} & \multirow[t]{2}{*}{ Class Color } \\
\hline $\begin{array}{l}\text { Tundra } \\
\text { Vegetation }\end{array}$ & $\begin{array}{c}\text { Herb } \\
\text { Dominated Tundra }\end{array}$ & & & \\
\hline "T" & $\begin{array}{c}\text { Shrub } \\
\text { Dominated Tundra }\end{array}$ & $\begin{array}{l}\text { upland tundra dominated by } \\
\text { tall shrubs }(>25 \mathrm{~cm})\end{array}$ & ST & \\
\hline \multirow{3}{*}{$\begin{array}{l}\text { Bare Ground } \\
\text { "B" }\end{array}$} & Sand & $\begin{array}{l}\text { sediment dominated by sand } \\
(0.0625-2.0 \mathrm{~mm})\end{array}$ & BS & \\
\hline & $\begin{array}{c}\text { Mixed } \\
\text { Sediment }\end{array}$ & $\begin{array}{c}\text { mixed sandy sediment } \\
\text { dominated by gravel, pebble } \\
\text { or cobble ( } 2.0-256.0 \mathrm{~mm}) \text { and } \\
\text { without woody debris }\end{array}$ & $\mathrm{BM}$ & \\
\hline & $\begin{array}{c}\text { Driftwood } \\
\text { Accumulation }\end{array}$ & $\begin{array}{l}\text { accumulations of driftwood } \\
(>80 \%)\end{array}$ & BW & \\
\hline \multirow{2}{*}{$\begin{array}{l}\text { Wetland } \\
\text { "W" }\end{array}$} & Wetland & $\begin{array}{c}\text { wetland vegetation } \\
\text { communities dominated by } \\
\text { grasses, sedges or rushes }\end{array}$ & WT & \\
\hline & $\begin{array}{c}\text { Inundated } \\
\text { Low Lying Tundra }\end{array}$ & $\begin{array}{l}\text { vegetated tundra at or } \\
\text { near a water body }\end{array}$ & WI & \\
\hline Water & $\begin{array}{c}\text { Permanent } \\
\text { Water Bodies }\end{array}$ & $\begin{array}{l}\text { ocean, inland lakes, } \\
\text { river channels and ponds }\end{array}$ & OL & \\
\hline
\end{tabular}

Further, Figure 2 provides example photographs of select land cover classes. In total, information from more than fifty ground truth sites were available. Additionally, the number of samples was increased using high resolution airborne imagery with less than one meter spatial resolution provided by [34]. The generation of the land cover reference database was completed and locations of homogenous land cover were digitized using the airborne imagery. The reference information was 
then available in polygon format. Afterward, random sampling was applied, in order to generate 200 samples for each of the land cover classes listed in Table 2. Note that each individual point was selected to represent homogenous information for a certain land cover class (i.e., areas of mixed land covers were avoided). Figure 1a shows the locations of some sites visited and indicates the centers of the manually digitized polygons that exhibited homogeneous land coverage in the airborne imagery.
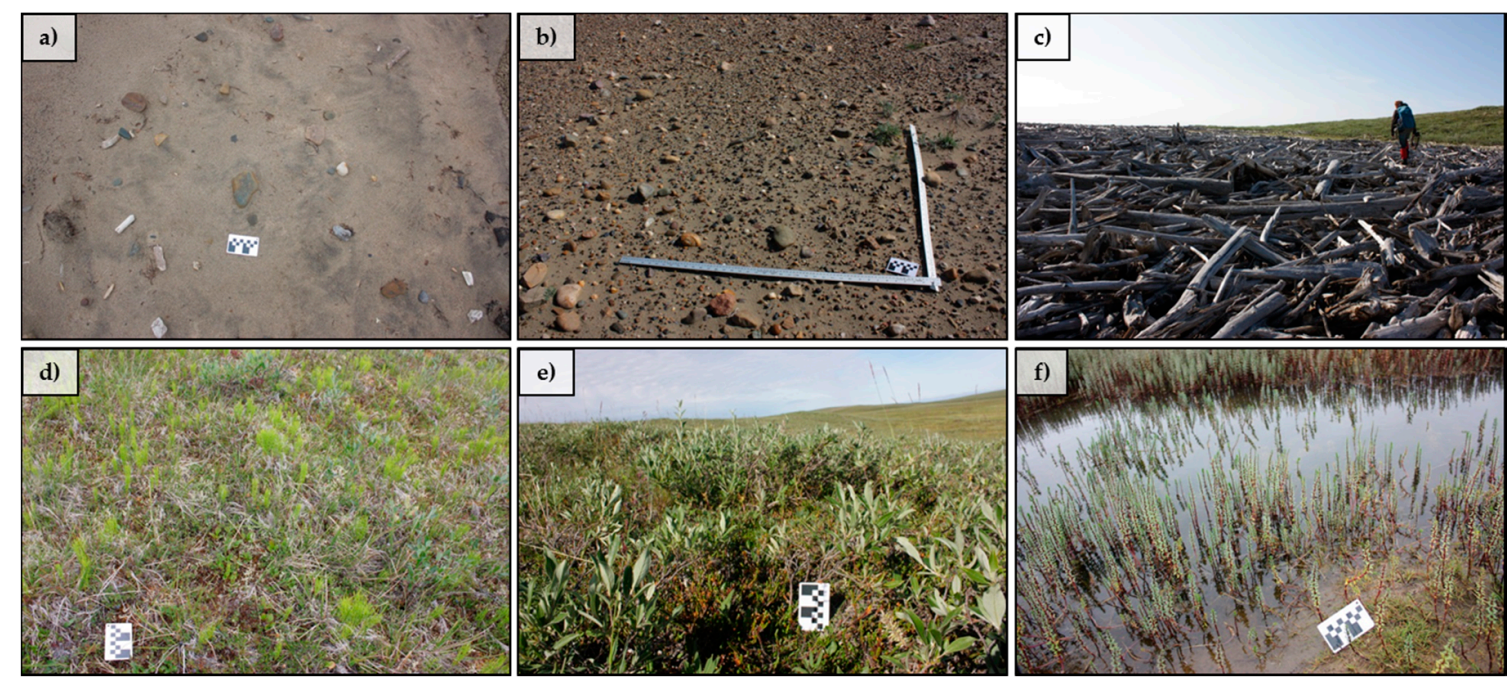

Figure 2. Example in situ imagery of select land cover classes of interest: (a) sand (BS); (b) mixed sediment (BM); (c) driftwood accumulation (BW); (d) herb dominated tundra (HT); (e) shrub dominated tundra (ST) and (f) wetland (WT). Photos were taken in 2012 on the Tuktoyaktuk Peninsula by Tobias Ullmann.

Additionally, a second set of 50,000 land samples was randomly generated, representing approximately $10 \%$ of all land pixels inside the common coverage of TSX, ALOS, ALOS-2 and R-2. This second set was generated independent of the land cover and was used to estimate the correlations among the PolSAR features. It is assumed that this sample represents the natural distribution of the relevant land cover classes.

\subsubsection{Polarimetric $S A R$ Data and Decompositions}

PolSAR data from R-2, TSX, ALOS and ALOS-2 were available for the test site. Table 3a lists the main acquisition parameters and shows that all data was acquired in the summer months, during the growing season of the tundra vegetation. Note that the ALOS-2 data was acquired at a steep incidence angle $\left(28^{\circ}\right)$ in 2016 , while the data of the other sensors were acquired with incidence angles between $34^{\circ}$ and $40^{\circ}$ in 2010/2011; along with the in situ reference data. Changes of the land cover were considered to be of less relevance for the analysis, considering the recent studies on the decadal changes in composition of the tundra vegetation here $[37,38]$ the spatial resolution of the data, and the rather broadly defined classes. Figure $1 \mathrm{~b}$ shows a false-color composite of the HV intensities of TerraSAR-X (TSX), R-2 and ALOS. 
Table 3. (a) Acquisition parameters of TerraSAR-X (TSX), Radarsat-2 (R-2), ALOS PALSAR (ALOS), and ALOS-2 PALSAR-2 (ALOS-2); (b) acquisition parameters of Landsat TM imagery and (c) overview on the polarimetric features considered in the analysis.

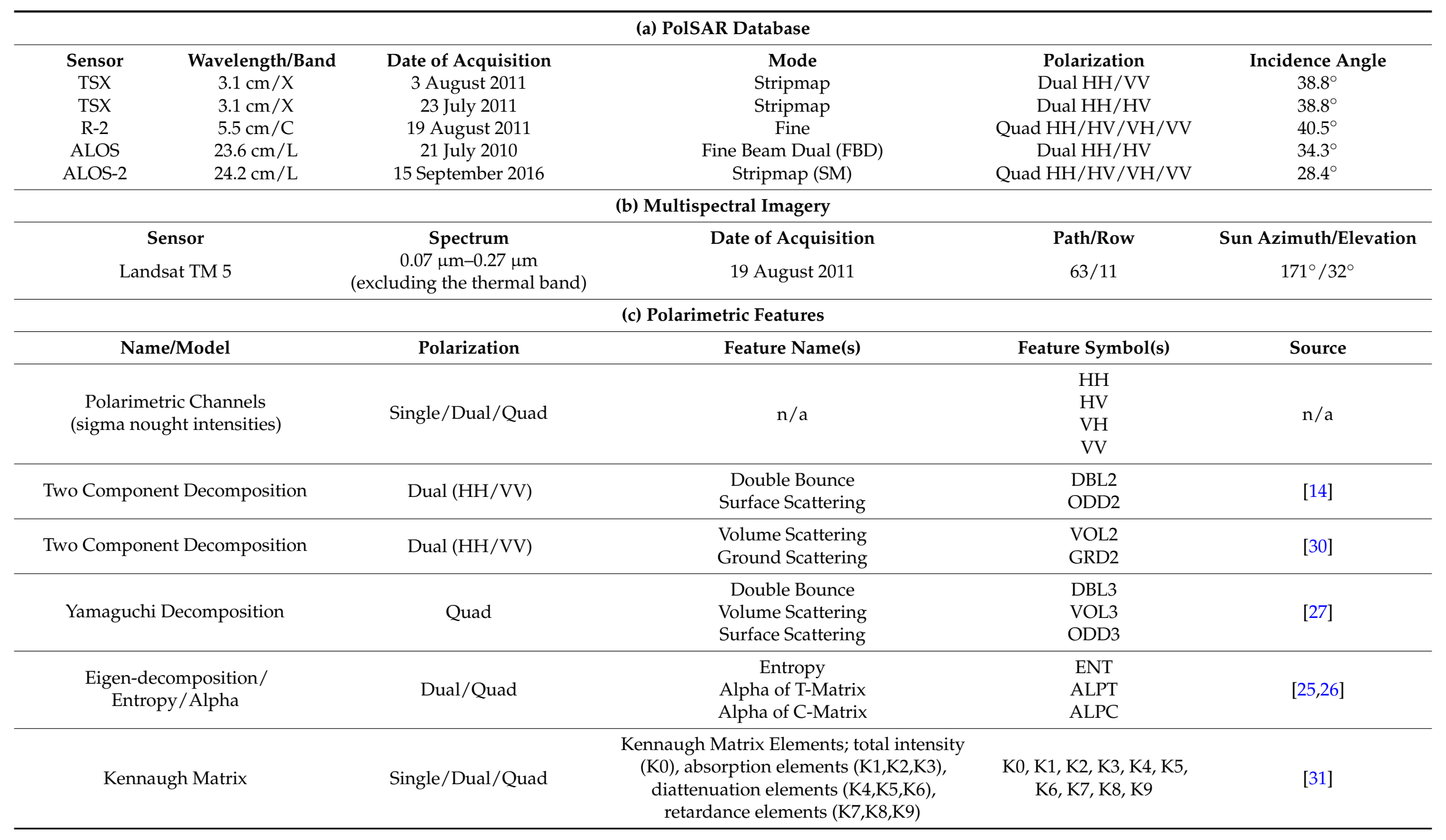


The following processing steps were applied to the PolSAR data: First, synthetic dual-polarized data $(\mathrm{HH} / \mathrm{VV}, \mathrm{VV} / \mathrm{VH}$ and $\mathrm{HH} / \mathrm{HV})$ were generated from the R-2 and the ALOS-2 quad-polarized data. These synthetic dual-polarized datasets were thus not affected by temporal variations and showed identical speckle characteristics (compared to the quad-polarized data from which the subsets were taken), as such, this allowed for direct comparison of class separability as a function of polarization diversity, as opposed to differences in moisture, and plant phenology. Second, the Sinclair scattering matrices of all dual- and quad-polarized data of all wavelengths were converted to the corresponding Kennaugh Matrices [31]. Third, the data were multi-looked (minimum of four looks) in order to generate pixels with square ground range resolution. Forth, a simple boxcar filter with a window size of $3 \times 3$ pixels was applied. Fifth, the data were terrain corrected and geocoded using the Range-Doppler Approach [39]. All data were transformed to UTM WGS1984 Zone 8 coordinate system with $12 \mathrm{~m}$ spatial resolution using the TanDEM-X intermediate digital elevation model (DEM) and the projected local incidence angle derived from this DEM [40]. The data were processed as sigma nought intensities.

All of the preceding steps were completed in SNAP 5.0 (Sentinel Application Platform) released by the European Space Agency (ESA), Paris, France. The terrain corrected Kennaugh Matrices were then used to generate the polarimetric channels, the Yamaguchi Decomposition [27], the Eigen-decomposition with the features Entropy/Alpha/Anisotropy, the Two Component Ground-Volume Decomposition of [30] and the Two Component Surface-Diherdal Decomposition of [14] using IDL 8.5 and ENVI 5.3. All intensity features were scaled to decibels [dB]. The above mentioned decompositions are explained in more detail in the subsequent paragraphs.

Kennaugh Matrix - For quad-polarized data the Kennaugh Matrix (Mueller Matrix, respectively [41]) describes the relation between the radiated and received wave as a symmetric $4 \times 4$ matrix using ten real elements (K0-K9). It is the linear transformation of the four-dimensional Stokes vector ([42] p. $43 \mathrm{ff}$. and p. $83 \mathrm{ff}$.) in the backscatter-alignment coordinate system. Unlike the Covariance or the Coherency Matrix, the Kennaugh Matrix can describe both coherent and incoherent targets [42,43]. The elements $\mathrm{K} 0, \mathrm{~K} 1$ and $\mathrm{K} 2$ are intensity-based elements, while $\mathrm{K} 3$ and $\mathrm{K} 4$ are based on the cross-polarized intensity and the co-polarized phase information. The elements $\mathrm{K} 5, \mathrm{~K} 6, \mathrm{~K} 7, \mathrm{~K} 8$ and $\mathrm{K} 9$ are phase-only elements that tend to provide unique information from natural targets. All elements of the full Kennaugh Matrix can be grouped as follows [31]: First, the total intensity (K0); second, the absorption elements that describe the loss of polarization during the scattering process (K1, K2, K3); third, diattenuation elements that describe the change of the relation between two amplitude values during reflection $(\mathrm{K} 4, \mathrm{~K} 5, \mathrm{~K} 6)$; fourth, retardance elements that describe the phase delay during scattering in a particular direction $(K 7, K 8, K 9)$. The definition of the Kennaugh Matrix and its elements for quad-polarized (A1), HH/VV-polarized (A2) and HH/HV- or VV/VH-polarized data (A3) are shown in Appendix A in accordance to [31]. The Kennaugh Matrix elements are linear combinations of the Coherency Matrix and combinations of K0, K1, K2 and K3 describe the diagonal elements of the Coherency Matrix $\left(\mathrm{T}_{11}, \mathrm{~T}_{22}, \mathrm{~T}_{33}\right.$ ), while combinations of $\mathrm{K} 4, \mathrm{~K} 5, \mathrm{~K} 6, \mathrm{~K} 7, \mathrm{~K} 8$ and $\mathrm{K} 9$ describe off-diagonal elements of the Coherency Matrix $\left(T_{12}, T_{13}, T_{21}, T_{23}, T_{31}, T_{32}\right)$ [42]. The conversions of the Kennaugh Matrix to $3 \times 3$ Coherency Matrix (T) of quad-polarized (A4) and $2 \times 2 \mathrm{~T}$ of HH/VV-polarized data (A5) are shown in Appendix A in accordance to [31]. To generate all Kennaugh matrix elements requires quadrature polarized data, thus only a portion of can be generated using dual polarized data. For HH/VV-polarized data the Kennaugh Matrix consists of the elements K0, K3, K4 and K7. For $\mathrm{HH} / \mathrm{HV}$ - and VV/VH-polarized data the Kennaugh Matrix consists of the elements K0, K1, K5 and K6 [31]. Figure 1c shows as a false-color composite of the Kennaugh Matrix elements K1, K2 and K3, which were processed using the quad-polarized R-2 data. For the purpose of comparison Figure 1d shows a Landsat TM true-color RGB composite acquired in summer 2011, concurrent with the R-2 imagery.

Eigen-decomposition-The Eigen-decomposition approach is a frequently used to process PolSAR data $[25,26]$. It decomposes the incoherent signal (usually stored in the Covariance or Coherency 
Matrix) using eigenvalues $(\lambda)$ and eigenvectors $\left(u_{x}\right)\left((1)\right.$ and (2)). In the formula ${ }^{H}$ denotes the conjugate transpose. Note that the eigenvalues of the Covariance or Coherency Matrix are the same, while the eigenvectors differ. For dual-polarized data two eigenvalues and eigenvectors are obtained (1); while for quad-polarized data three eigenvalues and eigenvectors are obtained (2) when reciprocity is anticipated due to a monostatic acquisition geometry. Consequently, identical scattering from HV and $\mathrm{VH}$ is assumed.

$$
\begin{gathered}
U=\lambda_{1} u_{1} u_{1}^{H}+\lambda_{2} u_{2} u_{2}^{H} \\
U=\lambda_{1} u_{1} u_{1}^{H}+\lambda_{2} u_{2} u_{2}^{H}+\lambda_{3} u_{3} u_{3}^{H}
\end{gathered}
$$

Entropy/Alpha / Anisotropy-The Eigen-decomposition was used to process additional features that describe scattering processes [25,26,42,43]. The polarimetric Entropy and Alpha Scattering angle describes the scattering properties of incoherent (natural) scatterers. Entropy (3) and (4) can be understood as the degree of randomness of the scattered signal and is described by the logarithmic sum of the pseudo probabilities $p$ of the eigenvalues, and ranges from zero to one. The polarimetric Alpha scattering angle is calculated as the sum of the inverse cosine of the absolute value of the first eigenvector element and is weighted by the pseudo probabilities $p$ (5). Cloude and Pottier also showed a third feature for quad-polarized data that is calculated via the ratio between the normalized difference of the second and third eigenvalue: the Anisotropy (6), which indicates the relevance of secondary scattering processes. Anisotropy, understood in the quad-polarimetric sense, is unavailable for dual-polarized data. In the formulas $n$ is equal to two for dual-polarized data and three for quad-polarized data. Note that Entropies of the Covariance or Coherency Matrix are the same, but the Alpha scattering angles are different due to the differences between the Eigenvectors.

$$
\begin{gathered}
p_{i}=\frac{\lambda_{i}}{\sum_{k=1}^{n} \lambda_{k}} \\
H=-\sum_{i=1}^{n} p_{i} \log _{n}\left(p_{i}\right) \\
\alpha=\sum_{i=1}^{n} p_{i} \cos ^{-1}\left(\left|u_{1 i}\right|\right) \\
A=\frac{\lambda_{2}-\lambda_{3}}{\lambda_{2}+\lambda_{3}}
\end{gathered}
$$

Model-Based Decompositions-Besides the Kennaugh Matrix elements, the polarimetric intensities and the Eigen-decomposition features, three Model-based decompositions were applied to the data which apply simplified, pre-defined scattering models. For the quad-polarized data of R-2 and ALOS-2, the Three Component Yamaguchi Decomposition [27] was applied. This approach decomposes the total backscattered energy $P_{\text {Total }}$ into the intensities of surface scattering $\left(P_{\text {surface }}\right)$, double bounce scattering $\left(P_{\text {double bounce }}\right)$ and volume scattering $\left(P_{\text {volume }}\right)(7)$. This frequently used approach is suitable for comprehending and characterizing predominant scattering processes in nature.

$$
P_{\text {Total }}=P_{\text {surface }}+P_{\text {double bounce }}+P_{\text {volume }}
$$

As shown by [14] the approach of Yamaguchi can be adopted for HH/VV-polarized data, by decomposing the total backscattered energy $P_{\text {Total }}$ into the intensities of surface scattering $\left(P_{\text {surface }}\right)$ and double bounce scattering $\left(P_{\text {double bounce }}\right)(8)$. The correlation between the corresponding features of this decomposition and the Yamaguchi Decomposition are then a function of the presence and power of volume scattering processes [14]. Specifically, features are more highly correlated if volume scattering is negligible.

$$
P_{\text {Total }}=P_{\text {surface }}+P_{\text {double bounce }}
$$

For HH/VV-polarized data the approach of [30] can be applied as an alternative dual-polarimetric decomposition technique. The approach involves a synthetized HV channel and the polarimetric $H$ 
(see the preceding paragraph) (see also [44]). This technique decomposes the total backscattered energy $P_{\text {Total }}$ into contributions from scattering from ground $\left(P_{\text {ground }}\right)$ and from vegetation $\left(P_{\text {volume }}\right)(9)$.

$$
P_{\text {Total }}=P_{\text {volume }}+P_{\text {ground }}
$$

The two component decompositions of $[14,30]$ were applied to the X-Band HH/VV data of TSX, to the synthetic HH/VV data of R-2 and ALOS-2. Table 3c lists all the polarimetric data that were used in this study, and provides abbreviations that are used hereafter to refer to each decomposition element. The descriptions of Figures 3 and 4 list all features that were processed for a certain type of polarized data, e.g., for $\mathrm{HH} / \mathrm{HV}$ or $\mathrm{HH} / \mathrm{VV}$ data.

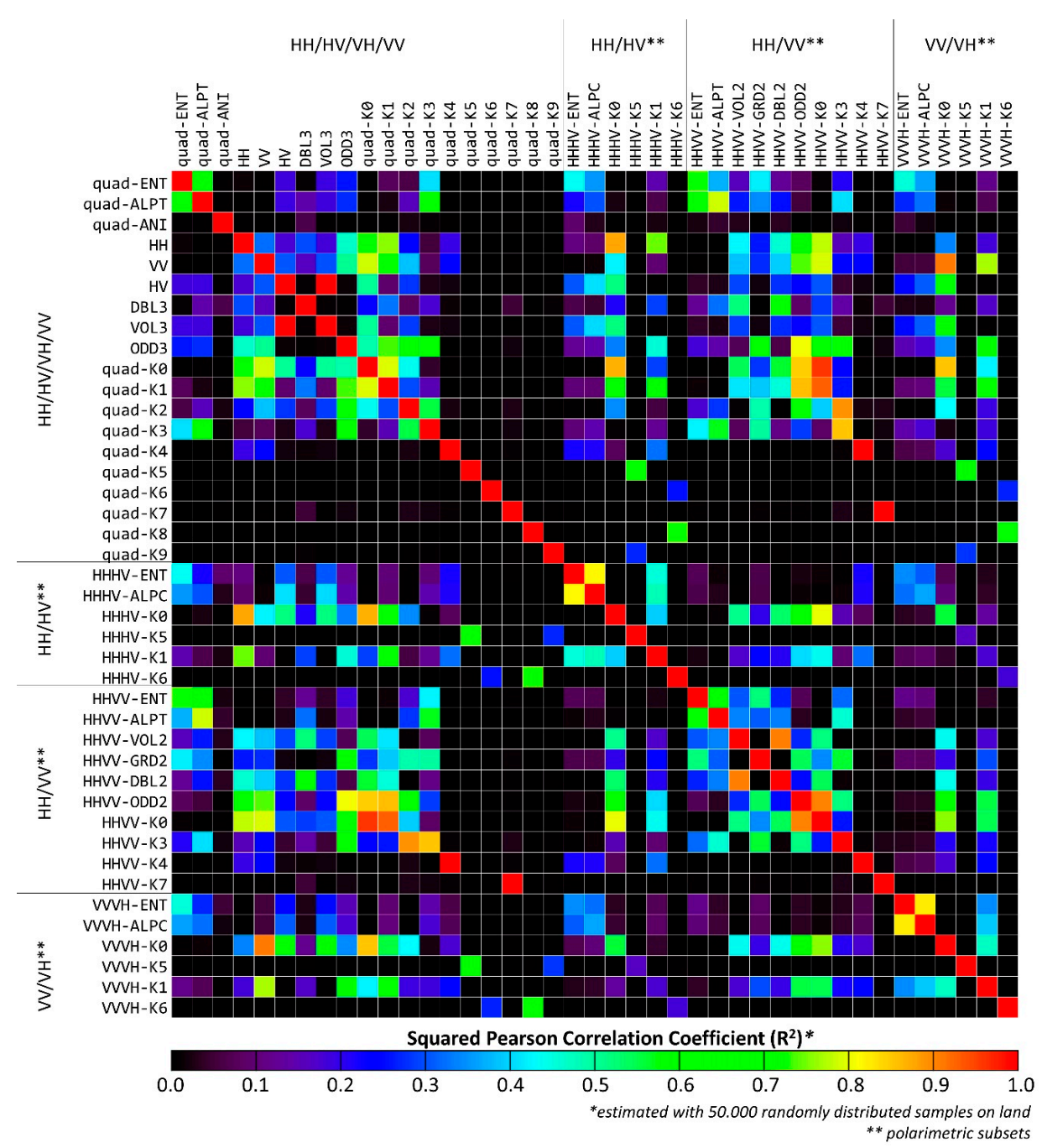

Figure 3. Correlation-Matrix of quad- and dual-polarimetric C-Band Radarsat-2 features showing the squared Linear Pearson Correlation Coefficient $\left(R^{2}\right)$ ranging from 0.0 (no correlation) to 1.0 (full linear correlation, determination respectively). $R^{2}$ was estimated using 50,000 randomly distributed samples on land (roughly $10 \%$ of all land pixels). Note that dual-polarimetric data of Radarsat- 2 were derived as polarimetric subsets and thus are not affected by temporal variations. Feature abbreviations are as follows (see Table 2): ENT (Entropy), ALPT (polarimetric Alpha scattering angle of Coherency Matrix), ALPC (polarimetric Alpha scattering angle of Covariance Matrix), HH/VV/VH (PolSAR Channels), DBL3 (double bounce of the Yamaguchi et al. Decomposition [27]), VOL3 (volume scattering of the Yamaguchi et al. Decomposition), ODD3 (surface scattering of the Yamaguchi et al. Decomposition), K0-K9 (elements of the Kennaugh Matrix [31]), VOL2 (volume scattering of [30]), GRD2 (ground scattering of [30]), DBL2 (double bounce of the [14]), ODD2 (surface scattering of the [14]). 


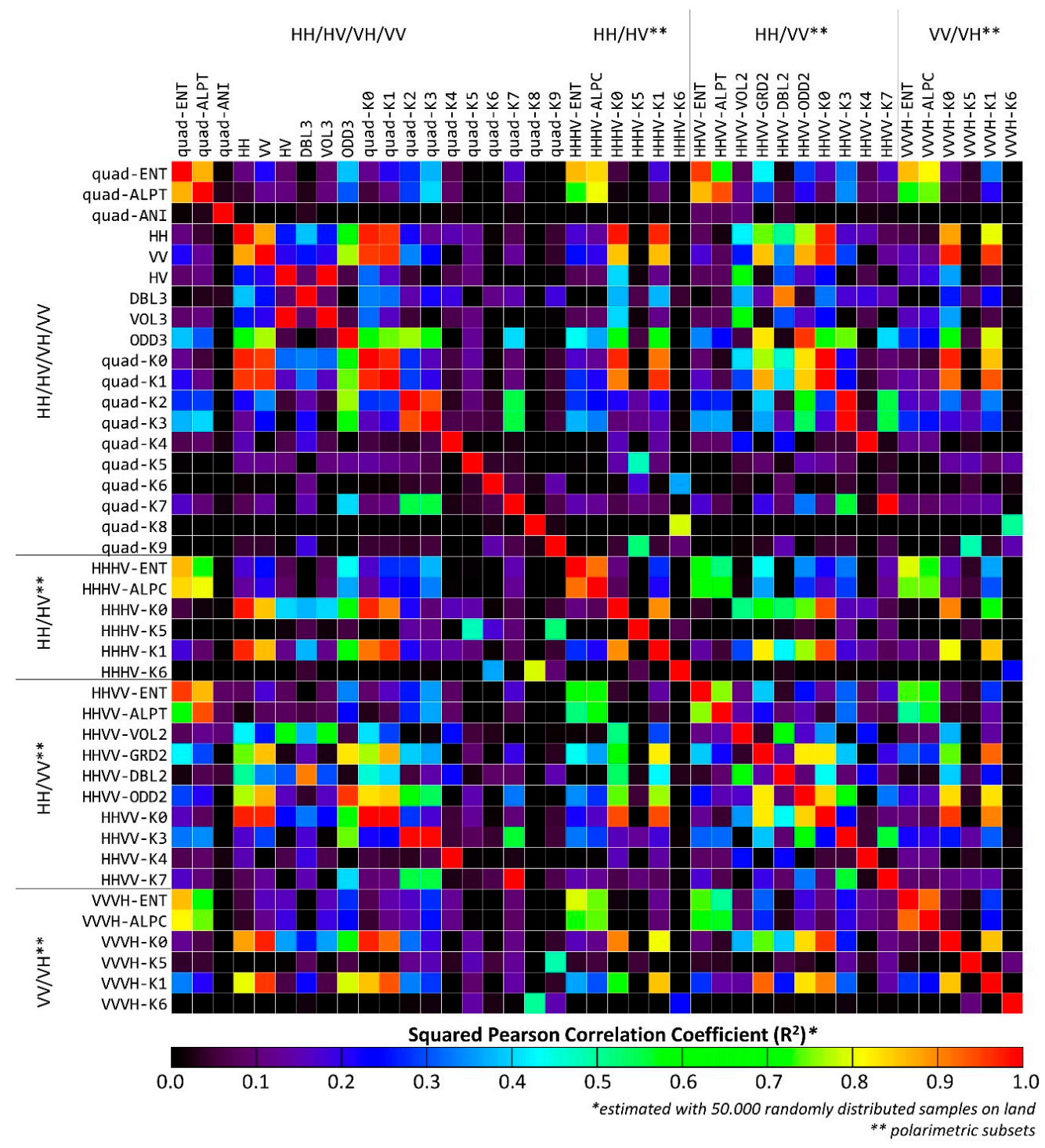

Figure 4. Correlation-Matrix of quad- and dual-polarimetric L-Band ALOS-2 features showing the squared Linear Pearson Correlation Coefficient $\left(R^{2}\right)$ ranging from 0.0 (no correlation) to 1.0 (full linear correlation, determination respectively). $R^{2}$ was estimated using 50,000 randomly distributed samples on land (roughly $10 \%$ of all land pixels). Note that dual-polarimetric data of ALOS-2 were derived as polarimetric subsets and thus are not affected by temporal variations. Feature abbreviations are as follows (see Table 2): ENT (Entropy), ALPT (polarimetric Alpha scattering angle of Coherency Matrix), ALPC (polarimetric Alpha scattering angle of Covariance Matrix), HH/VV/VH (PolSAR Channels), DBL3 (double bounce of the Yamaguchi et al. Decomposition [27]), VOL3 (volume scattering of the Yamaguchi et al. Decomposition), ODD3 (surface scattering of the Yamaguchi et al. Decomposition), K0-K9 (elements of the Kennaugh Matrix [31]), VOL2 (volume scattering of [30]), GRD2 (ground scattering of [30]), DBL2 (double bounce of [14]), ODD2 (surface scattering of [14]).

\subsection{Correlation, Class Separability, and Feature Selection}

The correlations between the above listed decomposition features were examined using the $\mathrm{dB}$-scaled sigma nought intensity values of the calibrated data, where applicable. Correlations were estimated using a random sample of 50,000 points over land (see Section 2.2.1. Land Cover Reference); thus values and analyses were completed independent of the land cover classes of interest. The squared linear Pearson Correlation Coefficient $\left(R^{2}\right)$ was used in all cases. The coefficient $R^{2}$ is defined as the squared ratio between the covariance $(\mathrm{Cov})$ of two variables $(i ; j)$ and the product of the individual 
standard deviations $\left(\sigma_{i} \sigma_{j}\right)(10) . R^{2}$ is frequently used to quantify the degree of determination between two variables, though still can be interpreted as a coefficient that quantifies the correlation. $R^{2}$ ranges from zero to one; a value of one (zero) indicates perfect (no) linear correlation and a maximum (minimum) determination, $100 \%(0 \%)$ of the explained variance, respectively [45].

$$
R^{2}=\left(\frac{\operatorname{Cov}(i, j)}{\sigma_{i} \sigma_{j}}\right)^{2}
$$

All PolSAR data were then used in separability analyses to quantify the ability of the polarimetric information to discriminate the land cover classes considered in this research. The Transformed Divergence (TD) (11) [45,46], Bhattacharyya Distance (BD) (12) [47], and Jefferys Matusita Distance (JD) (13) $[45,46]$ were processed for each PolSAR feature space and each wavelength for all land cover classes [47]. The features are processed for two classes $c$ and $d$ by assessing the classes' mean vectors $M(14)$ and the classes' covariance matrix $V$ (15) for a given set of features (as a minimum, two features are required). In the formula $t r$ denotes the trace of a matrix, formula det denotes the determinant of a matrix, ${ }^{\mathrm{T}}$ refers to the matrix/vector transpose, and $\operatorname{Cov}$ denotes the covariance. The separability features TD and JD have been shown to act as meaningful predictors for classification potential, thus a high separability indicates greater potential for class discrimination [48,49].

$$
\begin{gathered}
\mathrm{TD}=2000\left[1-\exp \left(\frac{-0.5\left(\operatorname{tr}\left[\left(V_{c}-V_{d}\right)\left(V_{d}^{-1}-V_{c}^{-1}\right)\right]+\operatorname{tr}\left[\left(V_{c}^{-1}+V_{d}^{-1}\right)\left(M_{c}-M_{d}\right)\left(M_{c}-M_{d}\right)^{\mathrm{T}}\right]\right)}{8}\right)\right] \\
\mathrm{BD}=0.125\left(M_{c}-M_{d}\right)^{T} 0.5\left(V_{c}+V_{d}\right)\left(M_{c}-M_{d}\right)+0.5 \log _{e} \frac{\operatorname{det}\left(0.5\left(V_{c}+V_{d}\right)\right)}{\sqrt{\operatorname{det}\left(V_{c}\right)} \sqrt{\operatorname{det}\left(V_{d}\right)}} \\
\mathrm{JD}=\sqrt{2\left(1-\mathrm{e}^{-B D}\right)} \\
M_{c}=\left(\begin{array}{c}
\mu_{c 1} \\
\mu_{c 2} \\
\vdots \\
\mu_{c n}
\end{array}\right) \\
V_{c}=\left(\begin{array}{ccc}
\operatorname{Cov}_{c}(1,1) & \cdots & \operatorname{Cov}_{c}(1, n) \\
\vdots & \ddots & \vdots \\
\operatorname{Cov}_{c}(n, 1) & \cdots & \operatorname{Cov}_{\mathcal{c}}(n, n)
\end{array}\right)
\end{gathered}
$$

The metrics TD and JD can further be used for feature selection in order to identify those that are most meaningful for class separation among a given set of features. This can be achieved by calculating the increase in separability (SI) (16): displayed as the amount of separability $(S P)$ that is gained when a feature of interest $(x)$, e.g., $\mathrm{K} 0$, is added to an existing feature space $(\mathrm{K})$. The average increase in separability can be processed by averaging the SI values of each possible feature combination, e.g., the increase in separability when $K 0$ is added to $\{K 1, K 2\}$ or $\{K 1, K 3\}$ or . ., $\{K 1, K 2, K 3\}$ or $\{\mathrm{K} 1, \mathrm{~K} 2, \mathrm{~K} 4\}$ or $\ldots,\{\mathrm{K} 1, \mathrm{~K} 2, \mathrm{~K} 3, \mathrm{~K} 4\}$ or $\{\mathrm{K} 1, \mathrm{~K} 2, \mathrm{~K} 3, \mathrm{~K} 5\}$ or $\ldots$, and so on.

$$
\mathrm{SI}_{X}=S P_{\{x \cup \mathrm{K}\}}-S P_{\{\mathrm{K}\}}
$$

The separability metrics were employed to demonstrate the differences between the PolSAR features, to gauge their use in classification, and to determine which land cover classes can be separated with the PolSAR features. All of the investigated separability distances require normally distributed data, or at least symmetrically distributed data. Such symmetric distribution properties can be assumed for most of the investigated features. 


\section{Results}

\subsection{Corrleation}

Correlations among the decomposition features of dual- and quad-polarized data were investigated prior to the assessment of the backscatter characteristics of the land cover classes and the separability of classes. The squared Pearson Correlation Coefficient $\left(R^{2}\right)$ was derived using the 50,000 randomly distributed samples on land, and which represented $10 \%$ of all land pixels inside the common coverage of the TSX, ALOS, ALOS- 2 and R-2 imagery. Results were drawn as correlation matrices for the features of C-Band data of R-2 in Figure 3, for features of L-Band data of ALOS-2 in Figure 4.

For C-Band data (Figure 3), it was observed that Kennaugh Matrix elements K4, K5, K6, K7, $\mathrm{K} 8$ and $\mathrm{K} 9$ of the quad-polarized data showed the lowest correlations among all other investigated decomposition features. An explanation for this is that the Kennaugh elements usually are uncorrelated, and that the elements $\mathrm{K} 5$ to $\mathrm{K} 8$ are phase-based elements, which are more or less stochastically fluctuating over natural targets [31]. The $R^{2}$ values were less than 0.4 with the exception of $K 4$ and K7. These features were highly correlated with $\mathrm{K} 4$ and $\mathrm{K} 7$ of $\mathrm{HH} / \mathrm{VV}$-polarized data $\left(R^{2}\right.$ values of about 0.9 ). This high degree of correlation is because $\mathrm{K} 4$ holds the relation of $\mathrm{HH}$ to $\mathrm{VV}$, which is not kept in other decompositions, and the same applies for K7. As well, the correlations between $\mathrm{K} 5$ and $\mathrm{K} 5$ of $\mathrm{HH} / \mathrm{HV}$ and VV/VH were moderately high $\left(R^{2}\right.$ values of about 0.6$)$. Similarly, the $R^{2}$ values of $\mathrm{K} 8$ and $\mathrm{K} 6$ of $\mathrm{HH} / \mathrm{HV}$ and $\mathrm{VV} / \mathrm{VH}$ were around 0.5 . The reason for these observations are most likely the similar polarimetric behavior (diagonal diattenuation [31]) only with different input channels ( $\mathrm{HH} / \mathrm{HV}$ and $\mathrm{VV} / \mathrm{VH}$, respectively).

The same observations were made for the L-Band data of ALOS-2 (Figure 4); however, correlations between the Kennaugh Matrix elements K4, K5, K6, K7, K8 and K9 of quad-, HH/VV-, HH/HV- and $\mathrm{VV} / \mathrm{VH}$-polarized data were generally higher. For example, correlation between $\mathrm{K} 7$ of quad-polarized Kennaugh Matrix and $\mathrm{K} 3$ of $\mathrm{HH} / \mathrm{VV}$-polarized Kennaugh Matrix showed $R^{2}$ values of about 0.5 . Among the Kennaugh Matrix elements K0, K1, K2 and K3 of quad-, HH/VV-, HH/HV- and $\mathrm{VV} / \mathrm{VH}$-polarized data, the following distinct linear correlations were observed: $\mathrm{K} 0$ of quad- and $\mathrm{HH} / \mathrm{VV}$-polarized Kennaugh Matrix showed $R^{2}$ values greater than 0.9 in the C-and L-Band; K3 of quad- and $\mathrm{HH} / \mathrm{VV}$-polarized Kennaugh Matrix showed $R^{2}$ values greater than 0.8 in the $\mathrm{C}$ - and L-Band; K0 of quad-, $\mathrm{HH} / \mathrm{HV}$ - and VV/VH-polarized Kennaugh Matrix showed $R^{2}$ values greater than 0.8 in the C- and L-Band. Again the correlations between the Kennaugh Matrix elements of quad-, $\mathrm{HH} / \mathrm{VV}-, \mathrm{HH} / \mathrm{HV}$ - and VV/VH-polarized data were generally higher in the L- than in the C-Band. Thus, most likely the L-Band data is more "stable" in a polarimetric sense due to a longer wavelength. Further, the high correlation of $\mathrm{K} 0$ of quad- and $\mathrm{HH} / \mathrm{VV}$-polarized Kennaugh Matrix is present since $\mathrm{HH}$ and VV record the vast majority of backscatter, while the HV contribution is negligible.

Among the model-based (power) decomposition features of quad- and HH/VV-polarized data, good correspondence between the DBL3 and DBL2 $\left(R^{2}\right.$ values of about 0.8$)$, the ODD3 and ODD2 ( $R^{2}$ values of about 0.7$)$, the VOL3 and VOL2 ( $R^{2}$ values of about 0.7 (L-Band) and 0.4 (C-Band)) and the ODD3 and GRD2 ( $R^{2}$ values of about 0.8 (L-Band) and 0.6 (C-Band)) was observed for both C- and L-Band data. The $R^{2}$ values between any of the model-based (power) decomposition features and any other polarimetric feature were lower than these observations, with the exception of VOL3 and HV showing $R^{2}$ values of about 0.95 (C- and L-Band). The reason for this observation can be seen in the low proportion of volume scattering for the tundra environment, making the influence of the cross-polarization component negligible, and decomposition features of quad- and HH/VV-polarized data highly correlated.

With respect to the Eigen-decomposition features, ENT and polarimetric Alpha scattering angles (ALPT / ALPC) were highly correlated between the ENT and the ALPT of HH/VV-polarized data, and this was true for both C- and L-Band ( $R^{2}$ values of about 0.7). Additionally, ENT and ALPT were highly correlated with each other, with $R^{2}$ values of about $0.7-0.8$ (quad- and HH/VV-polarized 
data) and ENT and ALPC were moderately correlated with $R^{2}$ values of about $0.4-0.5$ (HH/HV- and $\mathrm{VV} / \mathrm{VH}$-polarized data).

This is most likely because most reflection is recorded in $\mathrm{HH}$ and VV intensities, making their contributions higher than the intensities of $\mathrm{HV}$ or $\mathrm{VH}$. This leads to a high correlation between the $\mathrm{HH} / \mathrm{VV}$ - and quad-polarized decomposition features.

In summary, this assessment indicated that Kennaugh Matrix elements K0, K1, K3, K4 and K7 of quad- and $\mathrm{HH} / \mathrm{VV}$-polarized data of C- and L-Band were highly correlated and thus can be used interchangeably in some cases, e.g., for image classification. The Kennaugh Matrix elements K5 and $\mathrm{K} 6$ of quad- and cross-polarized data showed lower correlation coefficient values. The correlation was generally higher in the L-band, compared to the C-Band, which is likely a result of less interaction between the incident wave and the vegetation body of the long L-Band microwaves; less volume scattering occurs.

\subsection{Backscatter Characterisics}

Figure 5 provides boxplots—showing the minimum, lower quartile (25\%), median (50\%), upper quartile (75\%), maximum - of the land cover classes (see Table 2) for select polarimetric features of X-Band (TSX), C-Band (R-2) and L-Band (ALOS and ALOS-2). Figure 5a-i display the backscatter characteristics of the land cover classes concerning the $\mathrm{HH}, \mathrm{HV}$ and VV sigma nought intensities in decibels $(\mathrm{dB})$. Figure $5 \mathrm{j}-\mathrm{O}$ shows the information of the model-based (power) decomposition features of the Yamaguchi Decomposition of C-Band (R-2) and L-Band (ALOS-2) as DBLB3, VOL3 and ODD3; in $\mathrm{dB}$. Figure $5 \mathrm{p}-\mathrm{x}$ shows the boxplots of the land cover classes for the Kennaugh Matrix elements $\mathrm{K} 0, \mathrm{~K} 3$ and $\mathrm{K} 4$ of HH/VV-polarized X-Band (TSX), quad-polarized C-Band (R-2) and quad-polarized L-Band (ALOS-2) data in dB.

The class OL showed a unique range of intensity values in the $\mathrm{K} 0$ and VV of $\mathrm{X}$ - and $\mathrm{C}$ - Band, the VOL3 and ODD3 of C-Band, and the K4 and HV of X-, C- and L-Band data. The scattering differences between water and land were clearly pronounced, as water was generally characterized by a low intensity value. This is because water surface was relatively calm, thus it was not observed as rough; the shallow angle incidence angles of the X-and C-Band data, and the longer wavelength of the L-Band. If the water surface were to become rough due to higher wind speeds, higher intensity values of $\mathrm{K} 0$ would be observed, thus complicating the separation of the classes. In such cases it is assumed that K3 and K4 will still be suitable to separate land from water, since both are indicators for double bounce scattering, typically minimal for water. Further, BS and BM showed increased HH, VV, HV, DBL3 and ODD3 scattering at C- and L-Band compared to other classes. The range of values observed for the BW class was more unique for L-Band features, than X- and C-Band features. The most distinct values were for L-Band VOL3; as the BW's median value exceeded $+5 \mathrm{~dB}$, compared to the median value of all other land cover classes. Scattering from BW at L-Band is therefore characterized by high intensity values for $\mathrm{HH}$, VOL3 and ODD3, with medians of about $-10 \mathrm{~dB}$ and $-7 \mathrm{~dB}$; whereas at C-Band the scattering from BW is characterized by high HH and ODD3 intensities. The median intensity of BW is comparably low in X-Band HH and differences of BW's statistics to BS and HT are less pronounced. Thus, independent of wavelength and decomposition technique, the data were sensitive to scattering differences between land and water (OL), and between sandy bare ground (BS) and mixed non-vegetated sediment (BM). BM had higher backscatter than BS, which can be attributed to the higher surface roughness of BM (grain sizes of $2.0 \mathrm{~mm}-256.0 \mathrm{~mm}$ ) compared to BS (grain sizes of $0.0625 \mathrm{~mm}-2.0 \mathrm{~mm}$ ), which leads to higher backscatter intensities. The difference between HT and ST scattering is characterized by increased HV, VOL3, and K0 intensities at X- and C-Band; however, there is substantial overlap in their distributions and the differences between median values were small; ranging from $+2 \mathrm{~dB}(\mathrm{X}-\mathrm{Band} \mathrm{HV})$ to $+3 \mathrm{~dB}$ (C-Band VOL3) between HT and ST. The largest differences in HT and ST statistics were nevertheless found for VOL3 of the C-Band data, but the data ranges of HT and ST (lower quantile to upper quantile) also overlap the ranges of BM, BW, WI and WT. Therefore, the X- and C-Band showed higher volume scattering intensities from shrub dominated 
tundra (ST) compared to herb dominated tundra (HT). This is likely due to a higher proportion of volume scattering in the shrub plants, which is caused by the relatively short wavelength. Contrarily, the L-Band HV and volume scattering intensities (VOL3) were not sensitive to this difference.
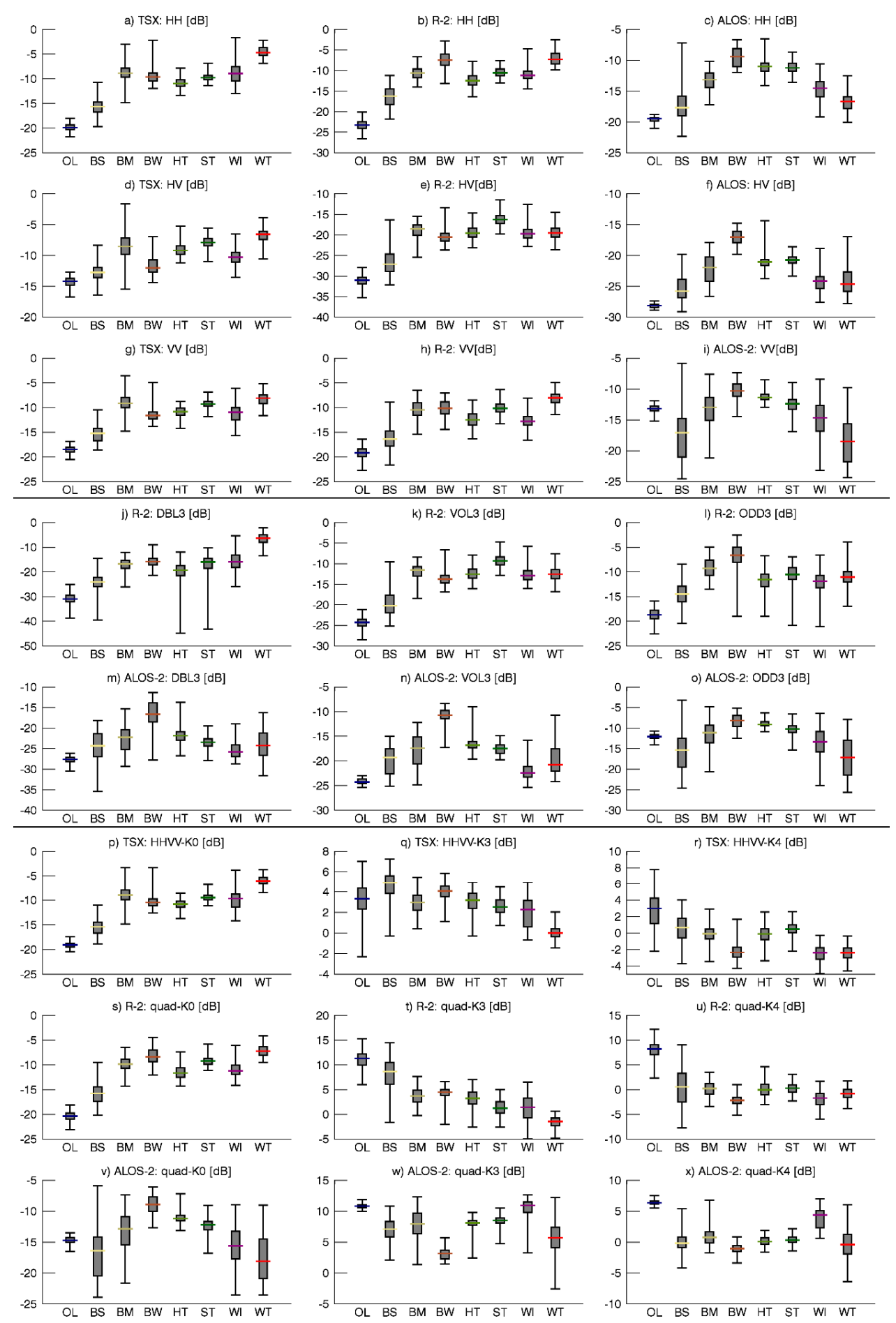

Figure 5. Boxplots (minimum, lower quartile (25\%), median (50\%), upper quartile (75\%), maximum) of (a-i) the polarimetric channels (HH/HV/VV) of TSX, R-2, ALOS and ALOS-2; (j-o) Yamaguchi Decomposition features (DBL3/VOL3/ODD3) of R-2 and ALOS-2; (p-x) Kennaugh Matrix elements (K0/K3/K4) of TSX, R-2 and ALOS-2 for the land cover classes OL (Permanent Water Bodies), BS (Sand), BM (Mixed Sediment), BW (Driftwood Accumulation), HT (Herb Dominated Tundra), ST (Shrub Dominated Tundra), WI (Inundated Low Lying Tundra) and WT (Wetland) (see Table 2). 
The L-Band HV channel and the volume scattering intensity of the Yamaguchi decomposition showed the same median values and comparable data ranges (lower to upper quantile) for these two land cover classes. At L-Band, the difference between HT and ST was better expressed via the VV channel, and the surface scattering intensity of the Yamaguchi decomposition via lower intensities of the ST compared to HT. This indicates an absence of volume scattering processes and a full penetration of the vegetation by the L-Band microwaves. Assuming that this observation is not caused by temporal variations present in the ALOS-2 data-which were acquired in 2016, while C-, X-Band and the land cover reference data were acquired in 2010/2011, the signal can be interpreted to represent backscattering mostly from the ground, as it is assumed that major changes in land cover type present have not occurred in this time.

The differences between the land cover classes WI and WT were characterized by increased DBL3, $\mathrm{K} 0, \mathrm{HH}$ and VV scattering in X- and C-Band and by K3 in X-, C- and L-Band. The statistics of WT showed a clear separation from the other land cover classes in the DBL3 and K3 of C-Band and the HH and $\mathrm{K} 3$ of $\mathrm{X}$-Band. The difference between the $\mathrm{WT}^{\prime} \mathrm{s}$ median value and the median value of any other land cover class exceeded $+5 \mathrm{~dB}$ in the X-Band HH and C-Band DBL3. The differences between wetland (WT) and inundated low-lying tundra (WI) was observed as higher $\mathrm{HH}$ and VV intensities-and the Kennaugh Matrix element K4 accordingly-in X- and C-Band and the double bounce intensity of the Yamaguchi decomposition. Further, both classes were characterized by comparably low values of the Kennaugh Matrix element K3, which points to distinct double bounce scattering, since $\Re\left(S_{H H} S_{V V}^{*}\right)$ is a known discriminator for this type of scattering (compare [27,31]). In contrast, both classes showed low intensities in the HH, VV and double bounce of the Yamaguchi decomposition at L-Band. Accordingly, $\mathrm{K} 3$ and $\mathrm{K} 4$ were less distinct and no double bounce scattering was present, when using the L-Band, which again is most likely due to the relatively short statured vegetation, the high penetration depth, and the absence of interactions between incident microwaves and the water surface and vegetation canopy.

In addition to the boxplots, Figure 6 shows scatterplots of the Kennaugh Matrix elements K0, K3 and $\mathrm{K} 4$ of X-, C- and L-Band data in order to investigate the scattering characteristics of the land cover classes in a multivariate feature space. Figure $6 \mathrm{a}-\mathrm{i}$ shows the position of the land cover reference in the $\mathrm{K} 0 / \mathrm{K} 3$ (left column), K0/K4 (center column) and K3/K4 (right column) feature spaces of X-Band (a-c), $\mathrm{C}$-Band $(\mathrm{d}-\mathrm{f})$ and L-Band $(\mathrm{g}-\mathrm{i})$. These results show that the feature space $\mathrm{K} 0 / \mathrm{K} 3$ of $\mathrm{X}$-and $\mathrm{C}$-Band facilitates the differentiation of the classes: OL, BS and WT; however, the position of values for BM, HT, ST and WI were indiscriminant from others. The feature space K0/K4 (Figure 6b,e,h) shows increased distance between samples of HT/ST and WI-especially at X-Band; however, a substantial degree of overlap between the samples of BM and BW, and the samples of HT, ST and WI was present. $\mathrm{K} 0$ provided the best separation between land cover classes at X-Band, C-Band, and L-Band. This is unsurprising since $\mathrm{K} 0$ of $\mathrm{X}$ - and C-Band showed a high positive linear correlation ( $R^{2}$ of 0.8 ) (Figure 6j). The combination of short- and longwave SAR facilitated the separation of the WI, BM and BW samples, and the features of X-/C- and L-Band showed no linear correlation $\left(R^{2}\right.$ less than 0.1) (Figure 6k,l). 

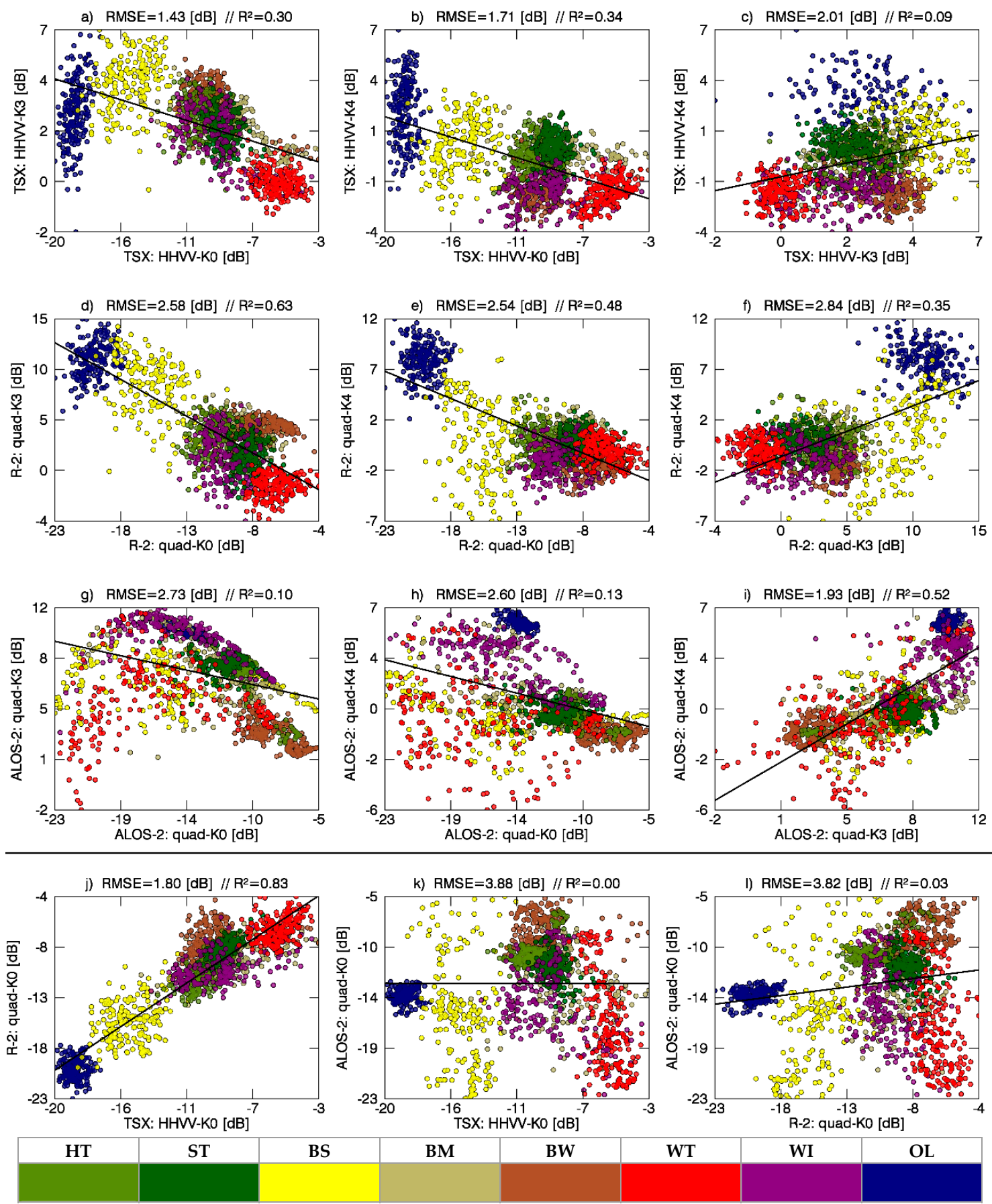

Figure 6. Scatterplots of the land cover classes OL (Permanent Water Bodies), BS (Sand), BM (Mixed Sediment), BW (Driftwood Accumulation), HT (Herb Dominated Tundra), ST (Shrub Dominated Tundra), WI (Inundated Low Lying Tundra) and WT (Wetland) (see Table 2) for: (a-c) Kennaugh elements K0/K3/K4 of HHVV-polarized X-Band (TSX); (d-f) Kennaugh elements K0/K3/K4 of quad-polarized C-Band (R-2); (g-i) Kennaugh elements K0/K3/K4 of quad-polarized L-Band (ALOS-2); (j-1) Kennaugh element K0 of TSX, R-2 and ALOS-2. In the figure title the Root-Means-Square-Error (RMSE) and the squared Linear Pearson Correlation Coefficient $\left(R^{2}\right)$ are drawn.

In summary, the X-, C- and L-Band data exhibit distinct scattering characteristics for the different land cover classes. All PolSAR data were sensitive to the OL, BS and BM coverage; additionally, L-Band data were most sensitive to the BW. The X-and C-Band features were suited to pronounce differences in WI and WT, and HT and ST coverage via the features HV, VOL3, DBL3, K0 and K3. 


\subsection{Class Separability and Feature Selection}

Multivariate assessment was completed for all feature spaces of the decomposition elements of dual- and quad-polarized X-, C- and L-Band datasets. The separabilities between classes (for the feature spaces of interest) were quantified for all possible combinations of variables (41) using the Transformed Divergence (TD) (Table 4) and the squared Jefferys Matusita Distance (JD) (Table 5). The feature spaces were ranked in descending order based on the average separability (AV) by the feature space of interest. For the purpose of comparison the tables also list separabilities achieved with the multispectral Landsat TM data using the six spectral bands (thermal information was excluded).

Results showed that the quad-polarized Kennaugh Matrices of ALOS-2 and R-2 offered the best separation of all land cover classes, followed by the HH/VV-polarized Kennaugh Matrices of ALOS-2, R-2 and TSX. The separability distances TD and JD further indicated that AV of ALOS-2 was comparable to the AV offered by multispectral data. As well, among the different PolSAR decompositions, the use of all Kennaugh Matrix elements was more beneficial for class separation than using the features of the model-based (power) Decompositions, Eigen-decompositions, or the intensities of the polarimetric channels. For C- and L-Band it was further observed that TD and JD of the Kennaugh Matrix decreased from quad-, to $\mathrm{HH} / \mathrm{VV}-$, to VV/VH- to HH/HV-polarized data.

For X-Band it was observed that TD and JD of the Kennaugh Matrix decreased from HH/VV- to $\mathrm{HH} / \mathrm{HV}$-polarized data. The separability of the Eigen-decomposition features ENT, ALPT or ALPC and ANI was low, and these feature spaces, as indicated by JD, offered the lowest separability between classes among all investigated feature spaces; independent of the wavelength (X-, C- or L-Band). With HH/VV-polarized data, the high correlation of Entropy and the Alpha scattering angles was observed by others [50], though. Another reason for this might be the lack of diversity of scattering processes in this rather "bare" landscape, thus the Entropy/Alpha feature space remains "unfilled" to a certain degree. Specifically, the tundra landscape examined in this research, offers a minor depolarizing, and low entropy environment.

The separability distance JD further outlined that the average class separability decreased from ENT/ALPT/ANI (quad) to ENT/ALPT (HH/VV) to ENT/ALPC (VV/VH) to ENT/ALPC (HH/HV). This might simply be a function of intensity, which decreased from quad to $\mathrm{HH} / \mathrm{VV}$ to VV/VH to $\mathrm{HH} / \mathrm{HV}$, since with lower intensities there is also lower information content. Among the land cover classes the classes OL, BS, BW and WT were shown to be the land cover classes with the highest average separability, thus the PolSAR data were especially suited to characterize these classes. The lowest average separability was observed for the land cover classes BM and WI, while separability of HT and ST was moderately high.

Table 6 draws the average increase of the separability features TD and JD for the ten elements of the quad-polarized Kennaugh Matrices (K0-K9) of C-Band (left column) and L-Band (right column) data. This assessment indicates that the average increase in separability when a feature of interest (K0-K9) is added to an existing feature space. This metric was used to identify the most important elements of the Kennaugh Matrix for class separation. For both C- and L-Band it was observed that $\mathrm{K} 0, \mathrm{~K} 1, \mathrm{~K} 2, \mathrm{~K} 3$ and $\mathrm{K} 4$ were more important for class separation than $\mathrm{K} 5, \mathrm{~K} 6, \mathrm{~K} 7, \mathrm{~K} 8$ and $\mathrm{K} 9$. An explanation for this observation is that $\mathrm{K} 0, \mathrm{~K} 1$ and $\mathrm{K} 2$ are intensity-based elements and are thus value are generally stable. $\mathrm{K} 3$ and $\mathrm{K} 4$ also use the cross-polarized intensity and the co-polarized phase, and are therefore relatively stable as well. Contrarily, K5, K6, K7, K8 and K9 are phase-based elements and therefore generally unstable in natural environments. With respect to the Coherency Matrix, K0 to $\mathrm{K} 4$ explain the diagonal elements which can be associated with dominant scattering processes, including: surface, double bounce and volume scattering. Hence (K5-K9, representing the off-diagonal elements of the Coherency Matrix, have minor relevance for the class separability. 
Table 4. Average class separability measured as Transformed Divergence (TD) for classes OL (Permanent Water Bodies), BS (Sand), BM (Mixed Sediment), BW (Driftwood Accumulation), HT (Herb Dominated Tundra), ST (Shrub Dominated Tundra), WI (Inundated Low Lying Tundra) and WT (Wetland) (see Table 2). TD is ranging from 0 to 2000; higher values indicate better class separation. The feature spaces are ranked in descending order of the average separability (AV). The black bars are scaled linearly between the minimum and maximum of AV. The colors from red to yellow to green correspond to the $10 \%, 50 \%$ and $90 \%$ quantiles of the AV.

\begin{tabular}{|c|c|c|c|c|c|c|c|c|c|c|c|c|}
\hline$\#$ & SENSOR & POL. & FEATURES & $\mathrm{OL}$ & BS & BM & BW & HT & ST & WI & WT & $\overline{\mathrm{AV}}$ \\
\hline 1 & ALOS-2 & quad & K-Matrix & 2000 & 1990 & 1963 & 1999 & 1999 & 2000 & 1973 & 2000 & 1991 \\
\hline 2 & Landsat TM & $\mathrm{n} / \mathrm{a}$ & (Band 1-5 \& 7) & 2000 & 1925 & 1925 & 2000 & 1993 & 1921 & 1926 & 2000 & 1961 \\
\hline 3 & ALOS-2 & HHVV & K-Matrix & 2000 & 1763 & 1593 & 1952 & 1930 & 1868 & 1849 & 1881 & 1854 \\
\hline 4 & $\mathrm{R}-2$ & quad & K-Matrix & 2000 & 1993 & 1640 & 1908 & 1680 & 1731 & 1782 & 1999 & 1842 \\
\hline 5 & ALOS-2 & quad & $\mathrm{HH} / \mathrm{HV} / \mathrm{VV}$ & 2000 & 1550 & 1439 & 1929 & 1796 & 1766 & 1817 & 1636 & 1742 \\
\hline 6 & ALOS & HHHV & K-Matrix & 2000 & 1681 & 1516 & 1914 & 1645 & 1717 & 1652 & 1740 & 1733 \\
\hline 7 & ALOS-2 & VVVH & K-Matrix & 2000 & 1521 & 1394 & 1961 & 1743 & 1621 & 1736 & 1661 & 1705 \\
\hline 8 & TSX & HHVV & K-Matrix & 1998 & 1934 & 1447 & 1574 & 1464 & 1605 & 1620 & 1966 & 1701 \\
\hline 9 & ALOS-2 & quad & DBL3/VOL3/ODD3 & 1999 & 1433 & 1353 & 1938 & 1787 & 1685 & 1696 & 1558 & 1681 \\
\hline 10 & ALOS-2 & HHHV & K-Matrix & 2000 & 1381 & 1334 & 1951 & 1838 & 1675 & 1514 & 1556 & 1656 \\
\hline 11 & ALOS-2 & VVVH & $\mathrm{VV} / \mathrm{VH}$ & 1999 & 1384 & 1265 & 1929 & 1680 & 1582 & 1657 & 1520 & 1627 \\
\hline 12 & $\mathrm{R}-2$ & HHVV & K-Matrix & 1998 & 1805 & 1282 & 1671 & 1306 & 1395 & 1442 & 1982 & 1610 \\
\hline 13 & TSX & HHHV & K-Matrix & 2000 & 1677 & 1320 & 1566 & 1488 & 1554 & 1311 & 1891 & 1601 \\
\hline 14 & ALOS-2 & HHHV & $\mathrm{HH} / \mathrm{HV}$ & 1995 & 1318 & 1211 & 1898 & 1727 & 1628 & 1538 & 1428 & 1593 \\
\hline 15 & $\mathrm{R}-2$ & quad & DBL3/VOL3/ODD3 & 1992 & 1875 & 1206 & 1529 & 1320 & 1633 & 1288 & 1893 & 1592 \\
\hline 16 & ALOS-2 & HHVV & DBL2 & 1997 & 1315 & 1177 & 1871 & 1745 & 1580 & 1465 & 1486 & 1579 \\
\hline 17 & ALOS-2 & HHVV & $\mathrm{VO}$ & 1995 & 1292 & 1188 & 1829 & 1770 & 1615 & 1433 & 1491 & 1577 \\
\hline 18 & ALOS & HHHV & $\mathrm{V}$ & 2000 & 1464 & 1249 & 1848 & 1410 & 1609 & 1349 & 1605 & 1567 \\
\hline 19 & TSX & HHVV & $\mathrm{V}$ & 1995 & 1883 & 1302 & 1289 & 1340 & 1530 & 1340 & 1848 & 1566 \\
\hline 20 & TSX & HHHV & $\mathrm{HH} / \mathrm{HV}$ & 1998 & 1657 & 1268 & 1401 & 1418 & 1485 & 1261 & 1844 & 1542 \\
\hline 21 & ALOS-2 & HHVV & $\mathrm{HH} / \mathrm{VV}$ & 2000 & 1401 & 1073 & 1562 & 1469 & 1462 & 1582 & 1476 & 1503 \\
\hline 22 & $\mathrm{R}-2$ & quad & $\mathrm{HH} / \mathrm{HV} / \mathrm{VV}$ & 1996 & 1865 & 1134 & 1459 & 1317 & 1464 & 1219 & 1561 & 1502 \\
\hline 23 & $\mathrm{R}-2$ & HHHV & ix & 1997 & 1849 & 1057 & 1362 & 1240 & 1429 & 1062 & 1560 & 1445 \\
\hline 24 & TSX & HHVV & DBL2 & 1995 & 1834 & 1046 & 1151 & 1187 & 1327 & 1030 & 1747 & 1415 \\
\hline 25 & $\mathrm{R}-2$ & HHVV & DBI & 1991 & 1755 & 984 & 1332 & 1136 & 1139 & 1031 & 1742 & 1389 \\
\hline 26 & TSX & HHHV & ENT & 1980 & 1344 & 1164 & 1218 & 1422 & 1308 & 1279 & 1390 & 1388 \\
\hline 27 & $\mathrm{R}-2$ & HHHV & $\mathrm{HH} / \mathrm{HV}$ & 1994 & 1844 & 970 & 1322 & 1221 & 1378 & 969 & 1334 & 1379 \\
\hline 28 & TSX & HHVV & VOL2/GRD2 & 1990 & 1811 & 1009 & 1009 & 1082 & 1235 & 983 & 1899 & 1377 \\
\hline 29 & ALOS-2 & quad & ENT/ALPT/ANI & 2000 & 1097 & 1001 & 1541 & 1339 & 1486 & 1245 & 1306 & 1377 \\
\hline 30 & $\mathrm{R}-2$ & VVVH & K-Matrix & 1990 & 1790 & 930 & 1060 & 1083 & 1327 & 1115 & 1535 & 1354 \\
\hline 31 & $\mathrm{R}-2$ & VVVH & $\mathrm{VV} / \mathrm{VH}$ & 1985 & 1803 & 882 & 1077 & 1100 & 1321 & 1076 & 1377 & 1328 \\
\hline 32 & R-2 & HHVV & $\mathrm{HH} / \mathrm{VV}$ & 1989 & 1672 & 970 & 1230 & 1087 & 1143 & 1051 & 1439 & 1322 \\
\hline 33 & R-2 & HHVV & VOL2/GRD2 & 1988 & 1729 & 909 & 1148 & 1075 & 1023 & 948 & 1573 & 1299 \\
\hline 34 & ALOS-2 & HHVV & ENT/ALPT & 2000 & 997 & 862 & 1426 & 1255 & 1281 & 1036 & 1264 & 1265 \\
\hline 35 & ALOS-2 & VVVH & ENT/ALPC & 2000 & 923 & 841 & 1763 & 868 & 979 & 1312 & 1152 & 1230 \\
\hline 36 & $\mathrm{R}-2$ & quad & ENT/ALPT/ANI & 1436 & 959 & 896 & 1110 & 1043 & 1241 & 1119 & 1924 & 1216 \\
\hline 37 & $\mathrm{R}-2$ & HHVV & ENT/ALPT & 1433 & 794 & 800 & 852 & 810 & 1009 & 1060 & 1911 & 1084 \\
\hline 38 & TSX & HHVV & ENT/ALPT & 1016 & 764 & 738 & 1234 & 807 & 830 & 1385 & 1788 & 1070 \\
\hline 39 & ALOS & HHHV & ENT/ALPC & 1445 & 1016 & 722 & 1123 & 877 & 840 & 875 & 1546 & 1056 \\
\hline 40 & ALOS-2 & HHHV & ENT/ALPC & 1580 & 814 & 599 & 1232 & 920 & 751 & 716 & 1019 & 954 \\
\hline 41 & R-2 & VVVH & ENT/ALPC & 1291 & 721 & 567 & 681 & 915 & 1131 & 849 & 914 & 883 \\
\hline 42 & $\mathrm{R}-2$ & HHHV & ENT/ALPC & 571 & 593 & 489 & 1058 & 838 & 1133 & 493 & 1092 & 784 \\
\hline
\end{tabular}


Table 5. Average class separability measured as squared Jefferys Matusita Distance (JD) for classes OL (Permanent Water Bodies), BS (Sand), BM (Mixed Sediment), BW (Driftwood Accumulation), HT (Herb Dominated Tundra), ST (Shrub Dominated Tundra), WI (Inundated Low Lying Tundra) and WT (Wetland) (see Table 2). JD is ranging from 0 to 2; higher values indicate better class separation. The feature spaces are ranked in descending order of the average separability (AV). The black bars are scaled linearly between the minimum and maximum of AV. The colors from red to yellow to green correspond to the $10 \%, 50 \%$ and $90 \%$ quantiles of the AV.

\begin{tabular}{|c|c|c|c|c|c|c|c|c|c|c|c|c|}
\hline$\#$ & SENSOR & POL. & FEATURES & $\mathrm{OL}$ & BS & BM & BW & HT & ST & WI & WT & $\mathrm{AV}$ \\
\hline 1 & ALOS-2 & quad & K-Matrix & 2.00 & 1.96 & 1.90 & 1.98 & 1.98 & 1.98 & 1.95 & 2.00 & 1.97 \\
\hline 2 & Landsat TM & $\mathrm{n} / \mathrm{a}$ & (Band 1-5 \& 7) & 2.00 & 1.91 & 1.84 & 2.00 & 1.94 & 1.83 & 1.83 & 2.00 & 1.92 \\
\hline 3 & $\mathrm{R}-2$ & quad & K-Matrix & 2.00 & 1.97 & 1.57 & 1.86 & 1.61 & 1.67 & 1.69 & 1.99 & 1.80 \\
\hline 4 & ALOS-2 & HHVV & K-Matrix & 1.99 & 1.51 & 1.31 & 1.82 & 1.69 & 1.60 & 1.64 & 1.64 & 1.65 \\
\hline 5 & TSX & HHVV & K-Matrix & 1.97 & 1.86 & 1.33 & 1.51 & 1.39 & 1.52 & 1.46 & 1.87 & 1.61 \\
\hline 6 & ALOS & HHHV & K-Matrix & 1.90 & 1.32 & 1.31 & 1.82 & 1.43 & 1.50 & 1.40 & 1.60 & 1.53 \\
\hline 7 & $\mathrm{R}-2$ & HHVV & K-Matrix & 1.97 & 1.68 & 1.22 & 1.58 & 1.24 & 1.32 & 1.31 & 1.95 & 1.53 \\
\hline 8 & ALOS-2 & quad & $\mathrm{HH} / \mathrm{HV} / \mathrm{VV}$ & 1.99 & 1.33 & 1.13 & 1.80 & 1.44 & 1.45 & 1.66 & 1.43 & 1.53 \\
\hline 9 & TSX & HHVV & $\mathrm{HH} / \mathrm{VV}$ & 1.96 & 1.79 & 1.20 & 1.25 & 1.26 & 1.45 & 1.20 & 1.76 & 1.48 \\
\hline 10 & ALOS-2 & quad & DBL3/VOL3/ODD3 & 1.95 & 1.21 & 1.06 & 1.81 & 1.40 & 1.42 & 1.54 & 1.38 & 1.47 \\
\hline 11 & ALOS-2 & VVVH & K-Matrix & 1.92 & 1.23 & 1.08 & 1.82 & 1.40 & 1.34 & 1.43 & 1.44 & 1.46 \\
\hline 12 & TSX & HHHV & K-Matrix & 1.96 & 1.55 & 1.07 & 1.39 & 1.27 & 1.41 & 1.16 & 1.80 & 1.45 \\
\hline 13 & $\mathrm{R}-2$ & quad & DBL3/VOL3/ODD3 & 1.94 & 1.68 & 1.09 & 1.44 & 1.16 & 1.45 & 1.17 & 1.67 & 1.45 \\
\hline 14 & ALOS-2 & HHHV & K-Matrix & 1.89 & 1.17 & 1.06 & 1.84 & 1.49 & 1.37 & 1.29 & 1.40 & 1.44 \\
\hline 15 & $\mathrm{R}-2$ & quad & $\mathrm{HH} / \mathrm{HV} / \mathrm{VV}$ & 1.97 & 1.70 & 1.07 & 1.35 & 1.20 & 1.37 & 1.15 & 1.49 & 1.41 \\
\hline 16 & TSX & HHHV & $\mathrm{HH} / \mathrm{HV}$ & 1.95 & 1.52 & 1.00 & 1.29 & 1.23 & 1.38 & 1.13 & 1.76 & 1.41 \\
\hline 17 & ALOS & HHHV & $\mathrm{HH} / \mathrm{HV}$ & 1.85 & 1.14 & 1.08 & 1.73 & 1.23 & 1.40 & 1.18 & 1.48 & 1.39 \\
\hline 18 & ALOS-2 & VVVH & $\mathrm{VV} / \mathrm{VH}$ & 1.96 & 1.10 & 0.96 & 1.75 & 1.27 & 1.28 & 1.47 & 1.29 & 1.39 \\
\hline 19 & R-2 & HHHV & K-Matrix & 1.97 & 1.65 & 0.99 & 1.30 & 1.15 & 1.33 & 0.98 & 1.46 & 1.35 \\
\hline 20 & ALOS-2 & HHVV & DBL2/ODD2 & 1.93 & 1.05 & 0.92 & 1.69 & 1.29 & 1.25 & 1.23 & 1.29 & 1.33 \\
\hline 21 & $\mathrm{R}-2$ & HHVV & DBL2/ODD2 & 1.93 & 1.59 & 0.96 & 1.28 & 1.09 & 1.07 & 0.99 & 1.71 & 1.33 \\
\hline 22 & TSX & HHVV & DBL2/ODD2 & 1.94 & 1.74 & 0.93 & 1.12 & 1.12 & 1.21 & 0.88 & 1.63 & 1.32 \\
\hline 23 & ALOS-2 & HHHV & $\mathrm{HH} / \mathrm{HV}$ & 1.86 & 1.05 & 0.89 & 1.76 & 1.30 & 1.26 & 1.28 & 1.17 & 1.32 \\
\hline 24 & ALOS-2 & HHVV & VOL2/GRD2 & 1.87 & 1.02 & 0.89 & 1.67 & 1.31 & 1.25 & 1.16 & 1.23 & 1.30 \\
\hline 25 & $\mathrm{R}-2$ & HHHV & $\mathrm{HH} / \mathrm{HV}$ & 1.96 & 1.64 & 0.91 & 1.21 & 1.11 & 1.28 & 0.91 & 1.27 & 1.29 \\
\hline 26 & TSX & HHVV & VOL2/GRD2 & 1.93 & 1.71 & 0.88 & 0.95 & 1.03 & 1.13 & 0.84 & 1.75 & 1.28 \\
\hline 27 & $\mathrm{R}-2$ & HHVV & $\mathrm{HH} / \mathrm{VV}$ & 1.96 & 1.56 & 0.94 & 1.20 & 1.05 & 1.07 & 1.03 & 1.39 & 1.28 \\
\hline 28 & ALOS-2 & HHVV & $\mathrm{HH} / \mathrm{VV}$ & 1.96 & 1.09 & 0.87 & 1.32 & 1.15 & 1.17 & 1.40 & 1.17 & 1.27 \\
\hline 29 & $\mathrm{R}-2$ & VVVH & K-Matrix & 1.91 & 1.56 & 0.88 & 1.01 & 1.02 & 1.25 & 1.04 & 1.44 & 1.26 \\
\hline 30 & ALOS-2 & quad & ENT/ALPT/ANI & 2.00 & 0.93 & 0.89 & 1.40 & 1.20 & 1.29 & 1.13 & 1.16 & 1.25 \\
\hline 31 & $\mathrm{R}-2$ & VVVH & $\mathrm{VV} / \mathrm{VH}$ & 1.90 & 1.54 & 0.84 & 1.00 & 1.01 & 1.26 & 1.01 & 1.32 & 1.23 \\
\hline 32 & $\mathrm{R}-2$ & HHVV & VOL2/GRD2 & 1.93 & 1.57 & 0.86 & 1.09 & 1.02 & 0.96 & 0.88 & 1.48 & 1.22 \\
\hline 33 & ALOS-2 & HHVV & ENT/ALPT & 1.99 & 0.83 & 0.77 & 1.27 & 1.10 & 1.09 & 0.95 & 1.14 & 1.14 \\
\hline 34 & TSX & HHHV & ENT/ALPC & 1.85 & 0.94 & 0.83 & 0.95 & 1.02 & 0.96 & 0.94 & 1.16 & 1.08 \\
\hline 35 & ALOS-2 & VVVH & ENT/ALPC & 1.92 & 0.76 & 0.73 & 1.47 & 0.76 & 0.86 & 1.14 & 0.99 & 1.08 \\
\hline 36 & $\mathrm{R}-2$ & quad & ENT/ALPT/ANI & 1.33 & 0.84 & 0.79 & 0.95 & 0.89 & 1.04 & 0.93 & 1.81 & 1.07 \\
\hline 37 & $\mathrm{R}-2$ & HHVV & ENT/ALPT & 1.36 & 0.73 & 0.73 & 0.77 & 0.74 & 0.88 & 0.88 & 1.80 & 0.99 \\
\hline 38 & TSX & HHVV & ENT/ALPT & 0.83 & 0.60 & 0.63 & 1.02 & 0.61 & 0.62 & 0.84 & 1.57 & 0.84 \\
\hline 39 & ALOS & HHHV & ENT/ALPC & 0.89 & 0.65 & 0.51 & 0.81 & 0.66 & 0.58 & 0.65 & 1.07 & 0.73 \\
\hline 40 & ALOS-2 & HHHV & ENT/ALPC & 1.14 & 0.57 & 0.46 & 0.98 & 0.64 & 0.55 & 0.52 & 0.81 & 0.71 \\
\hline 41 & $\mathrm{R}-2$ & VVVH & ENT/ALPC & 1.05 & 0.48 & 0.45 & 0.51 & 0.73 & 0.89 & 0.69 & 0.75 & 0.69 \\
\hline 42 & R-2 & HHHV & ENT/ALPC & 0.47 & 0.47 & 0.41 & 0.86 & 0.66 & 0.92 & 0.41 & 0.91 & 0.64 \\
\hline
\end{tabular}

For $\mathrm{C}$-Band it was further observed that $\mathrm{K} 0$ and $\mathrm{K} 1$ offered the highest increase for the separation of ST, while for L-Band K1 and K3 were more important for the separation of this land cover class. At C-Band, the information of K2 and K3 was beneficial for the separation of BW, WI and WT. The land cover class HT was best characterized by the elements $\mathrm{K} 0$ and $\mathrm{K} 2$ at C-Band and $\mathrm{K} 0, \mathrm{~K} 1$ and $\mathrm{K} 3$ at L-Band. This means that K0 (total backscattered intensity), K1 (absorption element showing the difference between co- and cross-polarized intensities), $\mathrm{K} 2$ and $\mathrm{K} 3$ (absorption elements that describe 
the loss of polarization during the scattering process) and K4 (diattenuation element showing the difference between $\mathrm{HH}$ and VV intensities) are good descriptors for the examined tundra land cover classes. The elements K7, K8 and K9 (descriptors of the phase delay during the scattering in a certain direction) play a minor role in the separation of classes, as phase delays happen during volume propagation. Since tundra vegetation has a relatively short stature (height), phase delays due to volume propagation are less likely.

Table 6. Average increase of the separability features: (a-b) Transformed Divergence (TD) and (c-d) squared Jefferys Matusita Distance (JD) for Kennaugh-Matrix elements K0-K9 of quad-polarimetric C-Band Radarsat-2 (left column) and L-Band ALOS-2 (right column) data and for classes OL (Permanent Water Bodies), BS (Sand), BM (Mixed Sediment), BW (Driftwood Accumulation), HT (Herb Dominated Tundra), ST (Shrub Dominated Tundra), WI (Inundated Low Lying Tundra) and WT (Wetland) (see Table 2). The features are ranked in descending order of the average increase in separability (AV). The last column displays the AV in percent (\%) The colors from red to yellow to green correspond to the $10 \%, 50 \%$ and $90 \%$ quantiles of the AV data range. The metric displays the average increase in separability when a feature of interest (K0-K9) is added to an existing feature space (see Section 2.3 Correlation, Class Separability and Feature Selection).

\begin{tabular}{|c|c|c|c|c|c|c|c|c|c|c|c|c|c|c|c|c|c|c|c|c|c|}
\hline \multicolumn{10}{|c|}{$\begin{array}{l}\text { C-Band Radarsat-2 } \\
\text { (a) Transformed Divergence (TD) }\end{array}$} & \multicolumn{12}{|c|}{$\begin{array}{l}\text { L-Band ALOS-2 } \\
\text { (b) Transformed Divergence (TD) }\end{array}$} \\
\hline & OL & BS & BM & BW & HT & ST & WI & WT & AV & $\%$ & & OL & BS & BM & BW & HT & ST & WI & WT & AV & $\%$ \\
\hline 0 & 100 & 193 & 150 & 183 & 226 & \begin{tabular}{|l|}
168 \\
\end{tabular} & 186 & 82 & 161 & 49.8 & & 30 & 115 & 172 & 65 & 109 & 91 & 92 & 56 & $\overline{91}$ & 10.2 \\
\hline & 99 & 129 & 37 & 143 & 182 & 129 & 224 & 163 & & & & 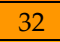 & 84 & 177 & & 86 & 115 & 99 & 43 & 0 & \\
\hline & 90 & 107 & 33 & & 11 & & & & & & & 4 & 00 & 62 & & & 00 & 03 & & 1 & .9 \\
\hline & 100 & 207 & 101 & 90 & 117 & \begin{tabular}{|l|}
173 \\
\end{tabular} & 1 & 37 & 0 & & & 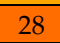 & 74 & 43 & & 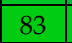 & 6 & 78 & 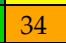 & 4 & 4 \\
\hline $\mathrm{Ka}$ & 97 & 92 & 63 & 116 & 61 & 73 & 118 & 19 & & 28 & & 36 & 47 & 103 & 30 & 42 & 84 & 145 & 30 & 5 & .7 \\
\hline K9 & 2 & 10 & 63 & 92 & 34 & 37 & 45 & 7 & & & & 23 & 74 & 97 & 2 & & 53 & 76 & & 0 & 0 \\
\hline & 1 & 14 & 29 & 32 & 3 & 22 & 4 & 9 & & & & 1 & 86 & 5 & 36 & 5 & & 4 & 38 & 40 & .0 \\
\hline & 5 & 11 & 52 & 4 & 29 & 2 & 3 & & & & & 1 . & 34 & & & & & 1 & 3 & & .7 \\
\hline & 6 & 12 & 19 & 4 & 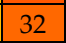 & 23 & 2 & & & & & 16 & 21 & & & & & 4 & & 1 & 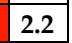 \\
\hline \multirow[t]{3}{*}{ K6 } & 2 & 7 & 16 & 46 & 27 & 13 & 14 & 11 & & & & 10 & 22 & 38 & 10 & 11 & 15 & 18 & 32 & 20 & .0 \\
\hline & \multicolumn{9}{|c|}{ (c) Jefferys Matusita Distance (JD) } & \multicolumn{12}{|c|}{ (d) Jefferys Matusita Distance (JD) } \\
\hline & OL & BS & BM & BW & HT & ST & WI & WT & AV & $\%$ & & OL & BS & BM & BW & HT & ST & WI & WT & $\mathrm{V}$ & $\%$ \\
\hline & 0.11 & 0.29 & 15 & 9 & 0.22 & Th & 0.19 & 0 & $E$ & 572 & & 0.0 & 0.16 & 0.24 & 0.14 & 0.1 & 0.16 & 0.20 & 0. & 16 & 18.3 \\
\hline & 0.10 & 0.19 & 13 & & 0 & & 0.2 & & & 51 & & 0.07 & 0.18 & 0.24 & 0.09 & 0.20 & 0.15 & 0.17 & 0.14 & & 17.6 \\
\hline & 0.09 & 0.15 & 0.13 & 16 & 0.11 & 0.14 & 0.15 & 0.1 & 14 & 45 & 1 & 0.09 & 0.15 & 0.24 & 0.12 & \begin{tabular}{|l|}
0.17 \\
\end{tabular} & \begin{tabular}{|l|}
0.16 \\
\end{tabular} & \begin{tabular}{|l|}
0.17 \\
\end{tabular} & 0.12 & 15 & 17.0 \\
\hline K1 & 0.11 & 0.25 & 0.10 & 0.09 & \begin{tabular}{|l|}
0.11 \\
\end{tabular} & \begin{tabular}{|l|}
0.19 \\
\end{tabular} & \begin{tabular}{|l|}
0.14 \\
\end{tabular} & 0.0 & 0.13 & 39 & & 0.06 & 0.13 & 0.22 & 0.10 & 0.15 & 0.14 & \begin{tabular}{|l|}
0.15 \\
\end{tabular} & 0.10 & 13 & 14.8 \\
\hline & .10 & 0.09 & 0.06 & & 0.06 & & 0.10 & & & 30 & & 0. & 0.09 & 0.13 & 0.04 & 0.08 & \begin{tabular}{|l|}
0.11 \\
\end{tabular} & 0.21 & 0.07 & 1 & 14.2 \\
\hline & 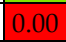 & 0.03 & 0.03 & 0.03 & 0.03 & c & 0.0 & 0.1 & & 6. & & 0.0 & 0.11 & 0.12 & 0.04 & 0.14 & \begin{tabular}{|l|}
0.11 \\
\end{tabular} & \begin{tabular}{|l|}
0.14 \\
\end{tabular} & 0.13 & & 13.0 \\
\hline & 0.00 & 0.02 & 0.05 & 0.08 & 0.03 & 0. & 0.04 & 0.0 & & & & 0.0 & 0.10 & 0.07 & 0.04 & 0.04 & 0.04 & 0.03 & 0.08 & & .2 \\
\hline 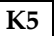 & 0.00 & 0.02 & 0.05 & 0.05 & \begin{tabular}{|l|}
0.03 \\
\end{tabular} & 0.02 & \begin{tabular}{|l|}
0.04 \\
\end{tabular} & 0.03 & 0.03 & & & 0.03 & 0.07 & 0.06 & 0.02 & \begin{tabular}{|l|}
0.06 \\
\end{tabular} & 0.05 & \begin{tabular}{|l|}
0.04 \\
\end{tabular} & 0.08 & 05 & 3 \\
\hline K8 & 0.00 & 0.02 & 0.02 & 0.05 & 0.03 & \begin{tabular}{|l|}
0.02 \\
\end{tabular} & \begin{tabular}{|l|}
0.03 \\
\end{tabular} & 0.0 & 0.03 & 4 & K8 & 0.02 & 0.04 & 0.05 & 0.02 & 0.03 & 0.03 & 0.03 & 0.09 & .04 & 4.3 \\
\hline K6 & 0.00 & 0.01 & 0.02 & 0.05 & 0.03 & 0.01 & 0.02 & 0.01 & 0.02 & 2.1 & K5 & 0.03 & 0.04 & 0.05 & 0.04 & 0.04 & 0.04 & 0.03 & 0.03 & 0.04 & \begin{tabular}{|l|}
4.0 \\
\end{tabular} \\
\hline
\end{tabular}

In summary, the class separability assessment indicated that the use of the full Kennaugh-Matrix is more beneficial than use of the model-based (power) Decompositions, Eigen-decompositions, or the intensities of the polarimetric channels. L-Band, followed by C-Band and X-Band showed the best separation concerning the different wavelengths. Using the PolSAR feature spaces was most beneficial for the separation of the land cover classes OL, BS, BW and WT.

\section{Discussion}

Correlation analyses of the PolSAR features indicated that the quad-polarized Kennaugh Matrix elements K0, K1, K3, K4 and K7 were highly correlated with corresponding elements of the dual-polarized Kennaugh Matrices. As the dual-polarized Kennaugh matrix is a submatrix of the full-polarized Kennaugh Matrix generated out of these elements, the elements are therefore interchangeable and the dual-polarized data provide a substitute of the full quad-polarized data, at least 
for the tundra land cover investigated in this research. Contrary to this, the quad-polarized Kennaugh Matrix elements K5 and K6 were less correlated to the corresponding elements of the cross-polarized Kennaugh Matrix. Nevertheless, there are still benefits associated with the Kennaugh Matrix, since all kinds of PolSAR data can be stored, processed and analyzed in the same manner. It also provides a unified framework without any loss of information, and the capacity to interpret decomposed elements in a coherent and incoherent way since any other incoherent or coherent scattering matrix can be derived if necessary [31,42]. The Stokes coordinate system used for the definition of the Kennaugh Matrix seems to offer an appropriate approach to characterize the environment investigated in this research.

For the examined tundra land cover of the Tuktoyaktuk Peninsula, it was further shown that the elements of the Two Component Decompositions of [14] and [30] were highly correlated with the corresponding elements of the Yamaguchi Decomposition and-with lower significance-volume scattering, and HV intensity, respectively. Thus, the HH/VV-polarized data provide crucial information for describing the land covers considered in this research. As pointed out by [14], the correspondence of these quad- and $\mathrm{HH} / \mathrm{VV}$-polarized decomposition features is a function of the presence and influence of volume scattering processes, relative to contributions from the ground. Thus, due to the relatively short stature (height) of tundra vegetation, the observed correlations were high due to a lack of a significant volume scattering component. Further, the correlations between the features were generally higher at L-Band, compared to features at C-Band. This can be attributed to the longer wavelength of the ALOS and ALOS-2 sensors, and the absence/weakness of random scattering processes as the penetration depth is higher and volume scattering is less likely (thus the volume component is small relative to surface scattering).

The backscatter characteristics of the tundra land cover classes were examined via box- and scatterplots of the individual PolSAR features. It was shown that X-, C- and L-Band data exhibit distinct scattering characteristics for the different land cover classes. Results indicate that the L-Band data were more sensitive to the bare ground classes; thus, it is better suited to investigate and monitor ground properties, e.g., soil moisture, or the surface heave and subsidence (via InSAR) caused by the freezing and thawing of the active layer (compare $[17,20,21]$ ); especially in sites dominated by shrubs. In contrast, use of short wavelengths (X-and C-Band) is beneficial for characterizing tundra and wetland vegetation. This observation is in accordance with other studies $[9,12,15]$.

It is worth noting the clear distinction of the land cover class: driftwood accumulation (BW) in the L-Band data. The coverage of BW is characterized by non-vegetated, dead woody debris, and frequently such accumulations exhibit a very high surface roughness, since dead wood and stems pile up more than a meter high (compare Figure 2c). Even though this should be a clearly visible target, and distinct feature in the PolSAR data, the position of BW is less clear in the feature spaces of $X$ - and C-Band compared to the position of BW in the L-Band feature space. For BW the highest $\mathrm{HH}$ and HV intensity values (derived from ALOS in 2010) were found among all land cover classes. As well, the scattering from this type of coverage was characterized by high volume scattering and double bounce intensities of the Yamaguchi decomposition (derived from ALOS-2 in 2016) at L-Band. The dielectric and geometric properties of the driftwood accumulations facilitate high intensity scattering at L-Band, thus this type of coverage is a "rough" target at L-band but not in C- and X-Band (i.e., because the logs are much larger than incident $C$ - and X-Band microwaves).

Even though the L-Band data showed limited value for characterizing the land cover classes HT, ST and WT using a single feature, the ALOS-2 quad-polarized and HH/VV-polarized data offered the feature space with the highest class separability; as indicated by the Transformed Divergence (TD) and squared Jefferys Matusita Distance (JD). However, since the ALOS-2 data were acquired at a steeper incidence angle and with a delay of six years, a true comparability of these results cannot be guaranteed. These results are therefore surprising, since one would assume a change of the land cover over time and an increasing dissimilarity between the reference and the PolSAR measurement with increasing temporal difference. Still, the ALOS HH/HV-polarized data acquired in 2010 showed 
a fairly good separability (Rank 17 in JD, Rank 18 in TD), and the data were observed to be more valuable for class separation than the C-Band (Rank 23 in JD, Rank 26 in TD), or X-Band (Rank 20 in TD, Rank 16 in JD) HH/HV-polarized data.

All separability features indicated that the Kennaugh Matrix was the most favorable feature space among all examined decompositions, which is in accordance with the expectation that full PolSAR information is better suited for class separability than is available via Entropy/Alpha, or the Two/Three Component Decomposition models, for instance. Among the Model-based Decompositions, the Yamaguchi Decomposition of quad-polarized data exceeded the separability offered by the Two Component Decomposition models. Thus, cross-polarized information is important for class discrimination, even though volume scattering processes play a minor role for the tundra environment investigated. Thus, perhaps differences in roughness/geometry play a more important role.

\section{Conclusions}

Results from this analysis indicate that the quad-polarized Kennaugh Matrix elements K0, K1, K3, K4 and K7 were highly correlated with corresponding elements of the dual-polarized Kennaugh Matrices; therefore, to a certain extent, dual-polarized data provide a useful substitute for the full quad-polarized data. The Kennaugh Matrix offers a unified framework to store, process and analyze PolSAR data in the same manner, and the Kennaugh elements offer comparable information from dualor quad-polarized data. Thus, there is nearly no difference between the two acquisitions modes when using Kennaugh elements.

Among the investigated Model-based Decompositions and the Eigen-decompositions the features of the Two Component Decompositions models of [14] (based on HH/VV dual-polarized data) were highly correlated with the corresponding elements of the Yamaguchi Decomposition (based on quad-polarized data). Independent of the wavelength and polarization mode, the Eigen-decomposition features Entropy and the Alpha scattering angles were highly correlated and of less value for class separation. Therefore, this approach does not seem suitable for this low depolarizing as well as low entropy environment.

The X-, C- and L-Band data exhibit distinct scattering characteristics for the different land cover classes. The PolSAR data of all wavelengths are sensitive to the land cover classes: open water (OL), sand (BS) and mixed sediment (BM); L-Band data were most sensitive to the BW; X- and C-Band features were most sensitive to the inundated low-lying tundra (WI) and wetland WT, and herb dominated tundra (HT) and shrub dominated tundra (ST). The use of shorter wavelengths (X-and C-Band) is beneficial for characterizing wetland vegetation. The L-Band data exhibited the differences of the bare ground classes BS, BM and BW best. Thus, in accordance to previous studies L-Band data are favorable for InSAR applications in this region, due to the observed distinct surface scattering and the low volume scattering contribution. In contrast, C- and X-Band data are favorable for the characterization of the tundra land cover due to the observed sensitivity of the cross- and co-polarized information to tundra vegetation.

Nevertheless, the assessment of the class separability pointed out that PolSAR data of any wavelength - also of L-Band-were valuable for class separation and PolSAR information is beneficial for class discrimination. The results showed that quad-polarized data of ALOS-2 and R-2 offered the best separation of the land cover classes, followed by the HH/VV-, HH/HV- or VV/VH-polarized data of ALOS-2, R-2 and TSX. Further, full PolSAR information is better suited for class separation than less diverse polarimetric feature spaces, like all dual-polarimetric measurements $(\mathrm{HH} / \mathrm{VV}, \mathrm{HH} / \mathrm{HV}$ or VV/VH). The Kennaugh Matrices offered the highest class separability among the investigated decompositions, and among the ten elements of the quad-polarized C- and L-Band Kennaugh Matrix the elements $\mathrm{K} 0, \mathrm{~K} 1, \mathrm{~K} 2, \mathrm{~K} 3$ and $\mathrm{K} 4$ were found to be most valuable for class discrimination. This also indicates that the phase-relation between $\mathrm{HH}$ and VV $(\mathrm{K} 3, \mathrm{~K} 4)$ provides crucial information for separating the investigated tundra land cover classes, since it contains the distinction of surface from 
diplane scattering. Further, the intensity-based information of the elements K0, K1 and K2, which explain the diagonal elements of the Coherency Matrix, are favorable for class discrimination.

In light of the results presented in this manuscript, future work should focus on investigating the combined use of short- and long-wave PolSAR data, e.g., of C-/X-Band and L-Band. It is anticipated that such multi-frequency data will provide complementary information useful for accurate classification and the description of land surface parameters, as well as biophysical parameters of the tundra vegetation. In this context, the combination of PolSAR information via a multi-sensor approach seems very promising, since it will combine dielectric, and geometrical properties of the targets.

An interesting future question will be to also address the use of hybrid-polarimetric/ compact-polarimetric data that can be synthetically generated from quad-polarimetric data, also using the Kennaugh Matrix approach [31]. The question will be how such data perform compared to quad-, or dual-polarized data.

As well, the potential for land cover classification should be addressed, e.g., via the Random-Forest approach that was shown to provide an interesting classification framework also for PolSAR data $[16,51]$. In this context, upcoming studies should further acknowledge if the Random-Forest approach is appropriate and essential for a successful PolSAR classification.

The inclusion of Sentinel-1 C-Band PolSAR data is another option, as the Interferometric Wide-Swath mode provides large spatial coverage at high spatial resolutions, and the planned continuity of the Sentinel SAR systems will offer the capacity to support long term monitoring and consistent remote observations of Arctic land covers. However, as shown in this study the VV/VH polarization mode, employed by Sentinel-1 over most parts of the Canadian Arctic, seems less suited for characterizing of the tundra land cover classes; thus the use of a multi-frequency or multi-sensor approach is advisable.

In summary, the SAR data of all wavelengths-also of the L-Band-were shown to provide important information about the tundra environment and utilization of such remotely sensed information is strongly recommended. PolSAR data provide unique information on dielectric, and geometrical properties that can help to increase the information space. Whenever possible dual- or quad-polarized data should be used, as polarimetry was shown to be of high value and importance.

Acknowledgments: The authors like to thank Achim Roth (DLR) and Roland Baumhauer (University of Wuerzburg) for the helpful discussions and support. Further, we like to thank Jason Duffe and Blair E. Kennedy (NWRC \& Carleton University Ottawa) for the organization of the field trip and the support during the field work. TerraSAR-X imagery is shown under permission of German Remote Sensing Data Center (DFD): Related Proposals COA1736 and COA1144. RADARSAT-2 imagery is shown under permission of MacDonald Dettwiler and Associates (MDA) - Related Multi-User Request Form MDA GSI-Ref.-Number: CG0061(2)-12-2011. ALOS and ALOS-2 imagery was obtained via the JAXA Proposal “Derivation of Environmental Parameters of Arctic Tundra Landscapes from Radar Remote Sensing"-PI No. 1186: Dr. Jennifer Sobiech-Wolf (Alfred Wegener Institute for Polar and Marin Research). This publication was funded by the German Research Foundation (DFG) in the funding program "Open Access Publishing" and by the University of Wuerzburg. The authors would like to thank the anonymous reviewers for their helpful and constructive comments.

Author Contributions: Tobias Ullmann, Sarah N. Banks and Andreas Schmitt conceived and designed the experiments; Tobias Ullmann and Sarah N. Banks performed the experiments; all authors analyzed the data and wrote the paper.

Conflicts of Interest: The authors declare no conflict of interest.

\section{Appendix A}

Definition of the Kennaugh Matrix and its elements for quad-polarized (A1), HH/VV-polarized (A2) and HH/HV- or VV/VH-polarized data (A3) is reported in the following and based on [31]. 
$S_{X X}$ and $S_{Y Y}$ refer to the complex signals of the co-polarized channels. $S_{X Y}$ refers to the complex signal of a cross-polarized channel.

$$
\begin{aligned}
& \mathbf{K}_{\text {quad }}=\left[\begin{array}{llll}
\mathrm{K} 0 & \mathrm{~K} 4 & \mathrm{~K} 5 & \mathrm{~K} 6 \\
\mathrm{~K} 4 & \mathrm{~K} 1 & \mathrm{~K} 9 & \mathrm{~K} 8 \\
\mathrm{~K} 5 & \mathrm{~K} 9 & \mathrm{~K} 2 & \mathrm{~K} 7 \\
\mathrm{~K} 6 & \mathrm{~K} 8 & \mathrm{~K} 7 & \mathrm{~K} 3
\end{array}\right] \text {, with } \\
& \mathrm{K} 0=0.5\left(\left|\mathrm{~S}_{X X}\right|^{2}+2\left|\mathrm{~S}_{X Y}\right|^{2}+\left|\mathrm{S}_{Y Y}\right|^{2}\right) \\
& \mathrm{K} 1=0.5\left(\left|\mathrm{~S}_{X X}\right|^{2}-\left|\mathrm{S}_{X Y}\right|^{2}-\left|\mathrm{S}_{Y X}\right|^{2}+\left|\mathrm{S}_{Y Y}\right|^{2}\right) \\
& \mathrm{K} 2=\Re\left(\mathrm{S}_{\mathrm{XX}} \mathrm{S}_{\mathrm{YY}}{ }^{*}-\mathrm{S}_{\mathrm{XY}} \mathrm{S}_{\mathrm{XY}}{ }^{*}\right) \\
& \mathrm{K} 3=-\Re\left(\mathrm{S}_{X X} \mathrm{~S}_{Y Y}{ }^{*}-\mathrm{S}_{\mathrm{XY}}{ }^{*} \mathrm{~S}_{\mathrm{XY}}\right) \\
& \mathrm{K} 4=0.5\left(\left|\mathrm{~S}_{X X}\right|^{2}-\left|\mathrm{S}_{X Y}\right|^{2}+\left|\mathrm{S}_{X Y}\right|^{2}-\left|\mathrm{S}_{Y Y}\right|^{2}\right) \\
& \mathrm{K} 5=\Re\left(\mathrm{S}_{X X} \mathrm{~S}_{X Y}{ }^{*}+\mathrm{S}_{X Y} \mathrm{~S}_{Y Y^{*}}\right) \\
& \mathrm{K} 6=\Im\left(\mathrm{S}_{X X} \mathrm{~S}_{X Y}{ }^{*}+\mathrm{S}_{X Y} \mathrm{~S}_{Y Y^{*}}{ }^{*}\right) \\
& \mathrm{K} 7=\Im\left(\mathrm{S}_{X X} \mathrm{~S}_{Y Y^{*}}{ }^{*}+\mathrm{S}_{X Y} \mathrm{~S}_{X Y}{ }^{*}\right) \\
& \mathrm{K} 8=\Im\left(\mathrm{S}_{\mathrm{XX}} \mathrm{S}_{\mathrm{XY}}{ }^{*}-\mathrm{S}_{\mathrm{XY}} \mathrm{S}_{\mathrm{Y}}{ }^{*}\right) \\
& \mathrm{K} 9=\Re\left(\mathrm{S}_{X X} \mathrm{~S}_{X Y}{ }^{*}-\mathrm{S}_{\mathrm{XY}} \mathrm{S}_{\mathrm{Y}}{ }^{*}\right) \\
& \mathbf{K}_{H H / V V .}=\left[\begin{array}{cccl}
\mathrm{K} 0 & \mathrm{~K} 4 & 0 & 0 \\
\mathrm{~K} 4 & 0 & 0 & 0 \\
0 & 0 & \mathrm{~K} 2 & \mathrm{~K} 7 \\
0 & 0 & \mathrm{~K} 7 & 0
\end{array}\right] \text {, with } \\
& \mathrm{K} 0=0.5\left(\left|\mathrm{~S}_{X X}\right|^{2}+\left|\mathrm{S}_{Y Y}\right|^{2}\right) \\
& \mathrm{K} 4=0.5\left(\left|\mathrm{~S}_{X X}\right|^{2}-\left|\mathrm{S}_{\mathrm{YY}}\right|^{2}\right) \\
& \mathrm{K} 3=-\Re\left(\mathrm{S}_{\mathrm{XX}} \mathrm{S}_{\mathrm{Y}}{ }^{*}\right) \\
& \mathrm{K} 7=\Im\left(\mathrm{S}_{X X} \mathrm{~S}_{Y Y^{*}}\right) \\
& \mathbf{K}_{X H H / H V \text { or } V V / V H .}=\left[\begin{array}{ccrl}
\mathrm{K} 0 & 0 & \mathrm{~K} 5 & \mathrm{~K} 6 \\
0 & \mathrm{~K} 1 & 0 & 0 \\
\mathrm{~K} 5 & 0 & 0 & 0 \\
\mathrm{~K} 6 & 0 & 0 & 0
\end{array}\right] \text {, with } \\
& \mathrm{K} 0=0.5\left(\left|\mathrm{~S}_{X X}\right|^{2}+2\left|\mathrm{~S}_{\mathrm{XY}}\right|^{2}\right) \\
& \mathrm{K} 1=0.5\left(\left|\mathrm{~S}_{X X}\right|^{2}-2\left|\mathrm{~S}_{X Y}\right|^{2}\right) \\
& \mathrm{K} 5=\Re\left(\mathrm{S}_{\mathrm{XX}} \mathrm{S}_{\mathrm{XY}}{ }^{*}\right) \\
& \mathrm{K} 6=\Im\left(\mathrm{S}_{X X} \mathrm{~S}_{X Y}{ }^{*}\right)
\end{aligned}
$$

Conversion of Kennaugh Matrix to $3 \times 3$ Coherency Matrix (T) of quad-polarized (A4) and $2 \times 2$ $\mathrm{T}$ of $\mathrm{HH} / \mathrm{VV}$-polarized data (A5) is defined according to [31,42] as:

$$
\begin{aligned}
& \mathbf{T}_{\text {quad }}=\left[\begin{array}{lll}
\mathrm{T}_{11} & \mathrm{~T}_{12} & \mathrm{~T}_{13} \\
\mathrm{~T}_{21} & \mathrm{~T}_{22} & \mathrm{~T}_{23} \\
\mathrm{~T}_{31} & \mathrm{~T}_{22} & \mathrm{~T}_{33}
\end{array}\right]= \\
& =\left[\begin{array}{ccc}
0.5(\mathrm{~K} 0+\mathrm{K} 1+\mathrm{K} 2-\mathrm{K} 3) & \mathrm{K} 4-\mathrm{iK} 7 & \mathrm{~K} 5+\mathrm{iK} 8 \\
\mathrm{~K} 4+\mathrm{iK} 7 & 0.5(\mathrm{~K} 0+\mathrm{K} 1-\mathrm{K} 2+\mathrm{K} 3) & \mathrm{K} 9+\mathrm{iK} 6 \\
\mathrm{~K} 5-\mathrm{iK} 8 & \mathrm{~K} 9-\mathrm{iK} 6 & 0.5(\mathrm{~K} 0-\mathrm{K} 1+\mathrm{K} 2+\mathrm{K} 3)
\end{array}\right]= \\
& \mathbf{T}_{\mathrm{HH} / \mathrm{VV}}=\left[\begin{array}{ll}
\mathrm{T}_{11} & \mathrm{~T}_{12} \\
\mathrm{~T}_{21} & \mathrm{~T}_{22}
\end{array}\right]=\left[\begin{array}{cc}
\mathrm{K} 0-\mathrm{K} 3 & \mathrm{~K} 4-\mathrm{iK} 7 \\
\mathrm{~K} 4+\mathrm{iK} 7 & \mathrm{~K} 0+\mathrm{K} 3
\end{array}\right]
\end{aligned}
$$




\section{References}

1. Jeffries, M.; Morris, K.; Liston, G. A method to determine lake depth and water availability on the North Slope of Alaska with spaceborne imaging radar and numerical ice growth modelling. ARCTIC 1996, 49, 367-374. [CrossRef]

2. Kozlenko, N.; Jeffries, M. Bathymetric mapping of shallow water in thaw lakes on the North Slope of Alaska with spaceborne imaging radar. ARCTIC 2000, 53, 306-316. [CrossRef]

3. Hall-Atkinson, C.; Smith, L.C. Delineation of delta ecozones using interferometric SAR phase coherence Mackenzie River Delta, N.W.T., Canada. Remote Sens. Environ. 2001, 78, 229-238. [CrossRef]

4. Hugenholtz, C.; Sanden, V.-D.J. Polarimetric SAR for Geomorphic Mapping in the Intertidal Zone, Minas Basinm Bay of Fundy, Nova Scotia; Natural Resources Canada \& Canadian Center for Remote Sensing: Ottawa, ON, Canada, 2011; pp. 1-28.

5. May, I.; Ludwig, R.; Bernier, M. Using TerraSAR-X imagery for the monitoring of permafrost dynamics in Northern Quebec. In Proceedings of the 4th TerraSAR-X Science Team Meeting, Oberpfaffenhofen, Germany, 14-16 February 2011; pp. 1-8.

6. Banks, S.N.; King, D.J.; Merzouki, A.; Duffe, J.; Solomon, S. Assessing Radarsat-2 polarimetric SAR for mapping shoreline cleanup and assessment technique (SCAT) classes in the Canadian. In Proceedings of the 32nd Canadian Symposium on Remote Sensing, Sherbrooke, QC, Canada, 13-16 June 2011; pp. 1-8.

7. Banks, S.; King, D.; Merzouki, A.; Duffe, J. Assessing RADARSAT-2 for mapping shoreline cleanup and assessment technique (SCAT) classes in the Canadian Arctic. Can. J. Remote Sens. 2014, 40, $243-267$. [CrossRef]

8. Sobiech, J.; Boike, J.; Dierking, W. Observation of melt onset in an arctic tundra landscape using high resolution TerraSAR-X and RADARSAT-2 data. In Proceedings of the 2012 IEEE International Geoscience and Remote Sensing Symposium (IGARSS), Munich, Germany, 22-27 July 2012; pp. 3552-3555.

9. Regmi, P.; Grosse, G.; Jones, M.; Jones, M.; Anthony, K. Characterizing post-drainage succession in thermokarst lake basins on the Seward Peninsula, Alaska with TerraSAR-X backscatter and Landsat-based NDVI data. Remote Sens. 2012, 4, 3741-3765. [CrossRef]

10. Jagdhuber, T.; Stockamp, J.; Hajnsek, I.; Ludwig, R. Identification of Soil Freezing and Thawing States Using SAR Polarimetry at C-band. Remote Sens. 2014, 6, 2008-2023. [CrossRef]

11. Ullmann, T.; Schmitt, A.; Roth, A.; Duffe, J.; Dech, S.; Hubberten, H.-W.; Baumhauer, R. Land Cover Characterization and Classification of Arctic Tundra Environments by Means of Polarized Synthetic Aperture X- and C-Band Radar (PolSAR) and Landsat 8 Multispectral Imagery-Richards Island, Canada. Remote Sens. 2014, 6, 8565-8593. [CrossRef]

12. Collingwood, A.; Treitz, P.; Charbonneau, F.; Atkinson, D. Artificial neural network modelling of high arctic phytomass using synthetic aperture radar and multispectral data. Remote Sens. 2014, 6, 2134-2153. [CrossRef]

13. Banks, S.; Millard, K.; Pasher, J.; Richardson, M.; Wang, H.; Duffe, J. Assessing the Potential to Operationalize Shoreline Sensitivity Mapping: Classifying Multiple Wide Fine Quadrature Polarized RADARSAT-2 and Landsat 5 Scenes with a Single Random Forest Model. Remote Sens. 2015, 7, 13528-13563. [CrossRef]

14. Ullmann, T.; Schmitt, A.; Jagdhuber, T. Two Component Decomposition of Dual Polarimetric HH/VV SAR Data: Case Study for the Tundra Environment of the Mackenzie Delta Region, Canada. Remote Sens. 2016, 8 , 1027. [CrossRef]

15. Widhalm, B.; Bartsch, A.; Leibmann, M.; Khomutov, A. Active-layer thickness estimation from X-band SAR backscatter intensity. Cryosphere 2017, 11, 483-496.

16. Brisco, B.; Short, N.; Budkewitsch, P.; Murnaghan, K.; Charbonneau, F. SAR interferometry and polarimetry for mapping and monitoring permafrost in Canada. In Proceedings of the 4th International Workshop on Science and Applications of SAR Polarimetry and Polarimetric Interferometry (PolInSAR 2009), Frascati, Italy, 26-30 January 2009; pp. 1-4.

17. Short, N.; Brisco, B.; Couture, N.; Pollard, W.; Murnaghan, K.; Budkewitsch, P. A comparison of TerraSAR-X, RADARSAT-2 and ALOS-PALSAR interferometry for monitoring permafrost environments, case study from Herschel Island, Canada. Remote Sens. Environ. 2011, 115, 3491-3506. [CrossRef]

18. Short, N.; LeBlanc, A.-M.; Sladen, W.; Oldenborger, G.; Mathon-Dufour, V.; Brisco, B. RADARSAT-2 D-InSAR for ground displacement in permafrost terrain, validation from Iqaluit Airport, Baffin Island, Canada. Remote Sens. Environ. 2014, 141, 40-51. [CrossRef] 
19. Schaefer, T. Remotely Sensed Active Layer Thickness (ReSALT) at Barrow, Alaska Using Interferometric Synthetic Aperture Radar. Remote Sens. 2015, 7, 3735-3759. [CrossRef]

20. Iwahana, G.; Uchida, M.; Liu, L.; Gong, W.; Meyer, F.J.; Guritz, R.; Yamanokuchi, T.; Hinzman, L. InSAR Detection and Field Evidence for Thermokarst after a Tundra Wildfire, Using ALOS-PALSAR. Remote Sens. 2016, 8, 218. [CrossRef]

21. Jia, Y.; Kim, J.-W.; Shum, C.K.; Lu, Z.; Ding, X.; Zhang, L.; Erkan, K.; Kuo, C.-Y.; Shang, K.; Tseng, K.-H.; et al. Characterization of Active Layer Thickening Rate over the Northern Qinghai-Tibetan Plateau Permafrost Region Using ALOS Interferometric Synthetic Aperture Radar Data, 2007-2009. Remote Sens. 2017, 9, 84. [CrossRef]

22. Larsen, J.; Anisimov, O.; Constable, A.; Hollowed, A.B.; Maynard, N.; Prestrud, P.; Prowse, T.; Stone, J. Polar Regions. In Climate Change 2014: Impacts, Adaptation, and Vulnerability-Part B: Regional Aspects. Contribution of Working Group II to the Fifth Assessment Report of the Intergovernmental Panel on Climate Change; Barros, V.R., Field, C.B., Dokken, D.J., Mastrandrea, M.D., Mach, K.J., Bilir, T.E., Chatterjee, M., Ebi, K.L., Estrada, Y.O., Genova, R.C., et al., Eds.; Cambridge University Press: Cambridge, UK, 2014; pp. 1567-1612.

23. Lawrence, D.M.; Slater, A.G.; Tomas, R.A.; Holland, M.M.; Deser, C. Accelerated Arctic land warming and permafrost degradation during rapid sea ice loss. Geophys. Res. Lett. 2008, 35, L11506. [CrossRef]

24. Romanovsky, V.E.; Smith, S.L.; Christiansen, H.H. Permafrost thermal state in the polar northern hemisphere during the international polar year 2007-2009: A synthesis. Permafr. Periglac. Proc. 2010, 21, 106-116. [CrossRef]

25. Cloude, S.R.; Pottier, E. A review of target decomposition theorems in radar Polarimetry. IEEE Trans. Geosci. Remote Sens. 1996, 34, 498-518. [CrossRef]

26. Cloude, S.R. The Dualpol Entropy/Alpha decomposition: A PALSAR case study. In Proceedings of the 3th International Workshop on Science and Applications of SAR Polarimetry and Polarimetric Interferometry (PolInSAR), Frascati, Italy, 22-26 January 2007.

27. Yamaguchi, Y.; Yajima, Y.; Yamada, H. A four-component decomposition of POLSAR images based on the Coherency Matrix. IEEE Trans. Geosci. Remote Sens. 2006, 3, 292-296. [CrossRef]

28. Freeman, A.; Durden, S. A three-component scattering model for polarimetric SAR data. IEEE Trans. Geosci. Remote Sens. 1998, 36, 963-973. [CrossRef]

29. Touzi, R.; Goze, S.; Le Toan, T.; Lopes, A.; Mougin, E. Polarimetric discriminators for SAR images. IEEE Geosci. Remote Sens. 1992, 30, 973-980. [CrossRef]

30. Jagdhuber, T.; Hajnsek, I.; Caputo, M.; Papathanassiou, K.P. Soil Moisture Estimation Using Dual-Polarimetric Coherent (HH/VV) TerraSAR-X and TanDEM-X Data. In Proceedings of the TSX/TDX Science Meeting, Oberpfaffenhofen, Germany, 10-14 June 2013.

31. Schmitt, A.; Wendleder, A.; Hinz, S. The Kennaugh element framework for multi-scale, multi-polarized, multi-temporal and multi-frequency SAR image preparation. ISPRS J. Photogramm. Remote Sens. 2015, 102, 122-139. [CrossRef]

32. Ecological Stratification Working Group (Canada); Center for Land and Biological Resources Research (Canada); State of the Environment Directorate, Canada. A National Ecological Framework for Canada; Centre for Land and Biological Resources Research, Research Branch, Agriculture and Agri-Food Canada: Ottawa, ON, Canada, 1996; pp. 1-132.

33. Burn, C.R.; Kokelj, S.V. The environment and permafrost of the Mackenzie Delta Area. Permafr. Periglac. Proc. 2009, 20, 83-105. [CrossRef]

34. NWT-Geomatics. Northwest Territories (NWT) Centre for Geomatics. 2016. Available online: http:geomatics. gov.nt.ca (accessed on 15 April 2017).

35. Government of Canada; Natural Resources Canada; Earth Sciences Sector; Canada Centre for Mapping and Earth Observation. GeoBase-Land Cover, Circa 2000 Vector Data Product Specifications; Centre for Topographic Information Earth Sciences Sector Natural Resources Canada: Ottawa, ON, Canada, 2009; pp. 1-21.

36. Corns, I.G.W. Arctic plant communities east of the Mackenzie Delta. Can. J. Bot. 1974, 52, 1731-1745. [CrossRef]

37. Moffat, N.D.; Lantz, T.C.; Fraser, R.H.; Olthof, I. Recent Vegetation Change (1980-2013) in the Tundra Ecosystems of the Tuktoyaktuk Coastlands, NWT, Canada. Arct. Antarct. Alp. Res. 2016, 48, 581-597. [CrossRef] 
38. Lantz, T.C.; Marsh, P.; Kokelj, S.V. Recent Shrub Proliferation in the Mackenzie Delta Uplands and Microclimatic Implications. Ecosystems 2013, 16, 47-59. [CrossRef]

39. Richards, J.A. Remote Sensing with Imaging Radar; Springer: Berlin/Heidelberg, Germany, 2009; pp. 1-361.

40. Ullmann, T.; Büdel, C.; Baumhauer, R. Characterization of Arctic Surface Morphology by Means of Intermediated TanDEM-X Digital Elevation Model Data. Z. Geomorphol. 2017, 61, 3-25. [CrossRef]

41. Guissard, A. Mueller and Kennaugh matrices in radar polarimetry. IEEE Trans. Geosci. Remote Sens. 1994, 32, 590-597. [CrossRef]

42. Cloude, S.R. Polarisation-Applications in Remote Sensing; Oxford University Press: Oxford, UK, 2009; pp. 1-453.

43. Lee, J.-S.; Pottier, E. Introduction to the Polarimetric Target Decomposition Concept. In Polarimetric Radar Imaging: From Basics to Applications; CRC Press: Boca Raton, FL, USA, 2009; pp. 1-422.

44. Jagdhuber, T.; Hajnsek, I.; Caputo, M.; Papathanassiou, K.P. Dual-Polarimetry for soil moisture inversion at X-Band. In Proceedings of the EUSAR, Berlin, Germany, 3-5 June 2014; pp. 1-4.

45. Jensen, J.R. Introductory Digital Image Processing: A Remote Sensing Perspective, 2nd ed.; Prentice Hall PTR: Upper Saddle River, NJ, USA, 1995; pp. 1-544.

46. Swain, P.H. A Result from Studies of Transformed Divergence; LARS Technical Reports; Laboratory Applications of Remote Sensing, Purdue University: West Lafayette, IN, USA, 1973; Volume 42, pp. 1-5.

47. Bhattacharyya, A. On a measure of divergence between two statistical populations defined by their probability distributions. Bull. Calcutta Math. Soc. 1943, 35, 99-109.

48. Mausel, P.W.; Kramber, W.J.; Lee, J.K. Optimal band selection for supervised classification of multispectral data. Photogramm. Eng. Remote Sens. 1990, 56, 55-60.

49. Swain, P.H.; Davis, S.M. Remote Sensing: The Quantitative Approach; McGraw Hill Book Company: New York, NY, USA, 1978.

50. Mitsunobu, S.; Kazuo, O.; Chan-Su, Y. On the eigenvalue analysis using HH-VV dual-polarization SAR data and its applications to monitoring of coastal oceans. In Proceedings of the SPIE Conference on Ocean Sensing and Monitoring V, Baltimore, MD, USA, 30 April-1 May 2013; p. 8724.

51. Heine, I.; Jagdhuber, T.; Itzerott, S. Classification and Monitoring of Reed Belts Using Dual-Polarimetric TerraSAR-X Time Series. Remote Sens. 2016, 8, 552. [CrossRef] 